\title{
Mechanistic Analysis of the Pump Cycle of the KdpFABC P-Type ATPase
}

\author{
Bojana Damnjanovic, ${ }^{\dagger, \ddagger}$ Annemarie Weber, ${ }^{\dagger, \ddagger}$ Meike Potschies, ${ }^{\dagger}$ Jörg-Christian Greie, ${ }^{\S}$ \\ and Hans-Jürgen Apell $*, \dagger, \ddagger$ \\ 'Department of Biology, University of Konstanz, 78464 Konstanz, Germany \\ ${ }^{\ddagger}$ Konstanz Research School Chemical Biology, University of Konstanz, 78464 Konstanz, Germany \\ ${ }^{\S}$ Department of Biology, University of Osnabrück, 49074 Osnabrück, Germany
}

ABSTRACT: The high affinity potassium uptake system $\mathrm{KdpFABC}$ is a unique type Ia P type ATPase, because it separates the sites of ATP hydrolysis and ion transport on two different subunits. KdpFABC was expressed in Escherichia coli. It was then isolated and purified to homogeneity to obtain a detergent solubilized enzyme complex that allowed the analysis of ion binding properties. The electrogenicity and binding affinities of the ion pump for $\mathrm{K}^{+}$and $\mathrm{H}^{+}$were determined in detergent solubilized complexes by means of the electro

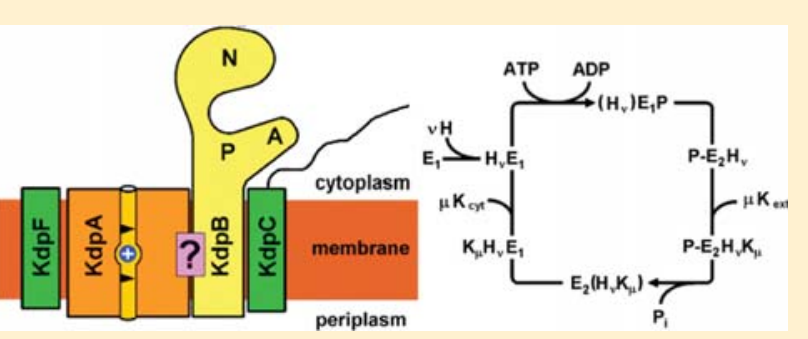
chromic styryl dye $\mathrm{RH} 421$. Half saturating $\mathrm{K}^{+}$concentrations and $\mathrm{pK}$ values for $\mathrm{H}^{+}$binding could be obtained in both the unphosphorylated and phosphorylated conformations of KdpFABC. The interaction of both ions with $\mathrm{KdpFABC}$ was studied in detail, and the presence of independent binding sites was ascertained. It is proposed that $\mathrm{KdpFABC}$ reconstituted in vesicles translocates protons at a low efficiency opposite from the well established import of $\mathrm{K}^{+}$into the bacteria. On the basis of our results, various mechanistic pump cycle models were derived from the general Post-Albers scheme of P type ATPases and discussed in the framework of the experimental evidence to propose a possible molecular pump cycle for KdpFABC.

\begin{abstract}
Tn bacteria, potassium ions are primarily used to maintain 1 turgor pressure. Additionally, cytoplasmic $\mathrm{K}^{+}$is essentially involved in $\mathrm{pH}$ homeostasis as well as in the activation of several enzymes. ${ }^{1}$ Because of the vital requirement to accumulate potassium ions in the cytoplasm, Escherichia coli comprises a set of different specialized potassium transport systems. ${ }^{2}$ Under $\mathrm{K}^{+}$limiting conditions (i.e., $\left[\mathrm{K}^{+}\right]_{\text {out }}<100 \mu \mathrm{M}$ ), the potassium transport systems $\operatorname{TrkG} / \mathrm{H}$, Kup, and $\mathrm{Ktr} A B$ are not able to provide a flow of $\mathrm{K}^{+}$into the bacteria that is sufficient to maintain the cytoplasmic concentrations needed for homeostasis. A high affinity potassium uptake system, the KdpFABC complex, is expressed in the case of such a deprivation. ${ }^{3,4}$ In this ion pump, coupling of ATP hydrolysis to ion transport leads to a high affinity uptake of potassium $\left(K_{\mathrm{M}} \leq 2 \mu \mathrm{M}\right)$ but only at moderate transport rates $\left[v_{\max }=150\right.$ $\mu \mathrm{mol}$ of $\left.\mathrm{P}_{\mathrm{i}}(\mathrm{g} \text { of protein })^{-1} \mathrm{~min}^{-1}\right]$ at $37{ }^{\circ} \mathrm{C} .{ }^{5} \mathrm{KdpFABC}$ belongs to the $\mathrm{P}$ type ATPase superfamily, but it has a unique subunit composition (Figure 1). P Type ATPases contain in general a central catalytic subunit that facilitates both ion transport and ATP hydrolysis according to the so called PostAlbers pump cycle (cf. Figure 12A). In contrast, the KdpFABC complex consists of four subunits, and the sites of ATP hydrolysis and ion transport are well separated on two different subunits. Only the KdpB subunit exhibits an explicit homology to other P type ATPases and represents the catalytic subunit performing ATP hydrolysis, whereas the KdpA subunit binds
\end{abstract}

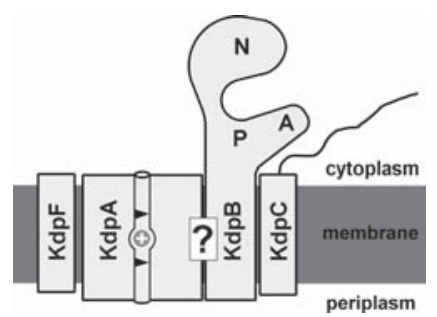

Figure 1. Schematic drawing of the KdpFABC complex according to Greie and Altendorf. The KdpB subunit, a P type ATPase, has to be coupled to the $\mathrm{KdpA}$ subunit, which resembles a bacterial $\mathrm{K}^{+}$channel to perform the observed uphill transport of $\mathrm{K}^{+} . \mathrm{N}, \mathrm{P}$, and A denote functional domains of $\mathrm{KdpB}$. For further explanation, see the text.

and transports $\mathrm{K}^{+}$and shows similarities to KcsA like $\mathrm{K}^{+}$ channel proteins. ${ }^{6,7}$

The KdpB subunit $(72 \mathrm{kDa})$ is comprised of the typical four functional and structural domains of P type ATPases: the transmembrane $(\mathrm{TM})$ domain, the nucleotide binding $(\mathrm{N})$ domain, the phosphorylation (P) domain, and the actuator (A) domain. As in the case of all $\mathrm{P}$ type ATPases, the conserved TGE motif was found in the A domain, which is supposed to 
approach the phosphorylation site in the $\mathrm{E}_{2} \mathrm{P}$ and $\mathrm{E}_{2}$ states of the enzyme. ${ }^{8}$ The $\mathrm{P}$ domain carries the strictly conserved DKTGT motif, with a reversibly phosphorylated aspartate residue. $^{9}$

Despite the similarities between the KdpA subunit ( $59 \mathrm{kDa})$ and potassium channels of the KcsA type, $\mathrm{K}^{+}$binding and transfer mechanisms have to be distinctly different. KcsA allows a passive diffusion of ions through a continuous pore crossing the membrane, whereas the $\mathrm{KdpA}$ subunit facilitates $\mathrm{K}^{+}$ transport against a concentration gradient utilizing the energy released in ATP hydrolysis and concomitantly prevents the transport of $\mathrm{K}^{+}$down the electrochemical potential gradient. ${ }^{7}$

The function of the $\mathrm{KdpC}$ subunit $(21 \mathrm{kDa})$ is still not clear, and it shows no homologies to any other known protein. Experiments have proven that it is essential for the function of the KdpFABC complex. ${ }^{10}$ It was considered to be a member of the FXYD protein family, like phospholamban or calmodulin, or like the $\gamma$ subunit of the $\mathrm{Na}, \mathrm{K}$ ATPase, which all regulate protein activity by interaction with catalytic subunits. ${ }^{11}$ Further experiments demonstrated that $\mathrm{KdpC}$ binds ATP with a binding constant in the millimolar range and that the hydrophilic portion of $\mathrm{KdpC}$ is able to interact with the catalytic domains of KdpB. ${ }^{12}$ This observation suggests that $\mathrm{KdpC}$ acts as a catalytic chaperone by binding an ATP molecule and/or guiding it into the nucleotide binding pocket of $\mathrm{KdpB} .^{7}$ Recent results showed that the interaction between $\mathrm{ATP}$ and $\mathrm{KdpC}$ is dependent on the presence of a conserved glutamine residue, also found in $\mathrm{ABC}$ transporters. Further more, the soluble domain of $\mathrm{KdpC}\left(\mathrm{KdpC}_{\text {sol }}\right)$ interacts with the $\mathrm{N}$ domain of $\mathrm{KdpB}$ in the proximity of the ATP binding pocket, thus forming a $\mathrm{KdpB}-\mathrm{KdpC}_{\text {sol }}-\mathrm{ATP}$ ternary complex and consequently increasing the ATP binding affinity. ${ }^{13}$ The $\mathrm{KdpF}$ subunit $(3 \mathrm{kDa})$ is proposed to act as a lipidlike stabilizer of the protein complex, and it can be replaced by a high concentration of E. coli lipids in vitro. ${ }^{14}$

The essential function of P type ATPases is a coupling between the energy releasing ATP hydrolysis and the energy consuming ion transport across membranes. For more than two decades, it has been established that the P type ATPases undergo a reaction cycle with large domain movements. This reaction cycle is known as the Post-Albers cycle. ${ }^{15,16}$ Its main feature is the fact that the ion pumps toggle between two main conformational states, $\mathrm{E}_{1}$ and $\mathrm{E}_{2}$, in which the ion binding sites alternatingly face one side of the membrane or the other. The pump process is driven by enzyme phosphorylation and dephosphorylation, and it performs sequential substrate binding-release reactions.

In this paper, the nature of the pumping process of $\mathrm{KdpFABC}$ was investigated. For this purpose, a fluorescence technique based on the voltage sensitive dye RH421 was employed, which allowed us to monitor ion movements in the membrane domain of ion transport proteins. The dye has been widely and successfully used for the characterization of the electrogenic partial reactions in the pump cycle of other P type ATPases. ${ }^{17-21}$ It was demonstrated recently that this method can be extended and successfully applied not only to the reconstituted protein but also to the detergent solubilized protein. $^{22}$ On the basis of this method, the electrogenicity of ion binding partial reactions of the pump cycle of the detergent solubilized KdpFABC was investigated. The apparent binding affinities for $\mathrm{K}^{+}$and $\mathrm{H}^{+}$were measured in both conformations, $\mathrm{E}_{1}$ and $\mathrm{E}_{2} \mathrm{P} . \mathrm{K}^{+}$binding titrations were conducted under different conditions to examine the influence of proton and
$\mathrm{Mg}^{2+}$ concentrations in the medium. To compare transport and enzyme activity, the dependence of ATP hydrolysis on the proton concentration was measured. In addition, the KdpFABC was reconstituted into lipid vesicles, and the electrogenic pump activity was studied using the fluorescent potential indicator $\operatorname{DiSC}_{3}(5)$.

\section{MATERIALS AND METHODS}

Materials. The total lipid extract from E. coli was purchased from Avanti Polar Lipids. The fluorescent dye RH421 was obtained from Molecular Probes (Eugene, OR) and $\mathrm{DiSC}_{3}(5)$ from Sigma Aldrich. ATP and valinomycin were obtained from Boehringer Mannheim. BioBeads SM 2 were purchased from Bio Rad. Ultrapure Pierce Water $\left(\left[\mathrm{K}^{+}\right]<10 \mathrm{ppb}\right)$ was obtained from Thermo Scientific. All other reagents were purchased from Merck or Sigma Aldrich at the highest available quality.

Bacterial Strains and Growth Conditions. The $k d p$ operon encoding the KdpFABC complex with a $\mathrm{C}$ terminal $\mathrm{His}_{14}$ tag at the KdpA subunit cloned in plasmid pGS4 was expressed in $E$. coli strain TKW3205 ( $\triangle k d p A B C^{\prime} 05$ nagA trkA405 trkD1 Datp706), with ampicillin as the selection marker, under the control of the wild type promoter as described previously. ${ }^{23,24}$ Cells were adapted to extremely low potassium concentrations promoting KdpFABC expression over a period of 3 days. Finally, minimal medium without potassium was inoculated with the preceding overnight culture, and protein expression was maintained by subsequent additions of $45 \mu \mathrm{M} \mathrm{KCl}$ at time points when cell growth reached a plateau level because of potassium deprivation. Cells were harvested by centrifugation at an optical density of $\sim 1$ at 600 $\mathrm{nm}$. Cell pellets were flash frozen in liquid nitrogen and stored at $-80{ }^{\circ} \mathrm{C}$.

Purification of the KdpFABC Complex. The $\mathrm{His}_{14}$ tagged KdpFABC complex was purified via metal chelate affinity immobilization, followed by size exclusion chromatography. ${ }^{24}$ In short, cells were lysed with a French press in $50 \mathrm{mM}$ Tris $\mathrm{HCl}$ (pH 7.5), $20 \mathrm{mM} \mathrm{MgCl} 2,10 \%$ (v/v) glycerol, and $0.5 \mathrm{mM}$ PMSF and supplemented with DNase I (Roche) and a protease inhibitor cocktail tablet (Roche). Membranes were collected by low speed centrifugation ( $10000 \mathrm{~g}$ for $15 \mathrm{~min}$ ) as the super natant and by centrifugation at $200000 \mathrm{~g}$ and $4{ }^{\circ} \mathrm{C}$ for $60 \mathrm{~min}$ as the pellet that was resuspended in $50 \mathrm{mM}$ Tris $\mathrm{HCl}(\mathrm{pH} 7.5)$, $10 \mathrm{mM} \mathrm{MgCl} 2,10 \%$ (v/v) glycerol, $1 \mathrm{mM} \mathrm{DTT}$, and $0.5 \mathrm{mM}$ PMSF at a protein concentration of $5 \mathrm{mg} / \mathrm{mL}$. The KdpFABC complexes were solubilized in aqueous solutions containing $1 \%$ $(\mathrm{w} / \mathrm{v})$ Aminoxide WS 35 for $1 \mathrm{~h}$ on ice. The solubilized protein was collected by centrifugation at $200000 \mathrm{~g}$ and $4{ }^{\circ} \mathrm{C}$ for $60 \mathrm{~min}$, and the supernatant was applied to a $5 \mathrm{~mL}$ HisTrap column (GE Healthcare), pre equilibrated with $50 \mathrm{mM}$ Tris $\mathrm{HCl}, 20$ $\mathrm{mM} \mathrm{MgCl} 2,10 \%$ (v/v) glycerol, $150 \mathrm{mM} \mathrm{NaCl}, 10 \mathrm{mM}$ imidazole ( $\mathrm{pH} 7.5), 0.5 \mathrm{mM}$ PMSF, and $0.2 \%(\mathrm{w} / \mathrm{v})$ Aminoxide WS 35. After three binding cycles, the HisTrap column was connected to a fast performance liquid chromatography system (Amersham, Biotech). The column was washed with the same buffer containing $20 \mathrm{mM}$ imidazole at a flow rate of $0.5 \mathrm{~mL} / \mathrm{min}$. Thereafter, the enzyme was eluted with buffer containing $130 \mathrm{mM}$ imidazole. Samples of the protein containing fractions were analyzed on a $12.5 \%$ sodium dodecyl sulfate-polyacrylamide gel electrophoresis (SDSPAGE) gel. Afterward, those fractions containing KdpFABC subunits in stoichiometric amounts were collected and concentrated (Vivaspin 6, 50000 molecular weight cutoff, Sartorius) to a volume of $500 \mu \mathrm{L}$. The sample was loaded on a 
Superdex 200 column (GE Healthcare), pre equilibrated with $50 \mathrm{mM}$ Tris $\mathrm{HCl}$ (pH 7.5), $150 \mathrm{mM} \mathrm{NaCl}, 0.5 \mathrm{mM}$ PMSF, and $0.2 \%(\mathrm{w} / \mathrm{v})$ Aminoxide WS 35, and eluted at a flow rate of 0.5 $\mathrm{mL} / \mathrm{min}$. Fractions were analyzed again on a SDS-PAGE gel, and the fractions of the purified complexes were concentrated as described above. Analogous preparations were conducted with different detergents: Fos choline $12, \beta \mathrm{DDM}, \beta \mathrm{DM}$, PCC $\alpha \mathrm{M}$, and LAPAO. In each preparation, the detergent concentration was also $1 \%(\mathrm{w} / \mathrm{v})$ for $\mathrm{KdpFABC}$ solubilization and $0.2 \%(\mathrm{w} / \mathrm{v})$ for further purification.

Determination of the Protein Concentration and ATPase Activity. The protein concentration in membrane vesicles was determined using the bicinchoninic acid assay (Pierce) according to the manufacturer's protocol. The concentration of the detergent solubilized protein was determined by the Lowry assay. ATPase activities of purified complexes were determined at $37^{\circ} \mathrm{C}$ using the malachite green activity assay. ${ }^{25}$ The specific ATP hydrolyzing enzyme activity was determined as the difference in $\mathrm{P}_{\mathrm{i}}$ produced per milligram of protein per minute from ATP hydrolysis by KdpFABC in the presence of saturating $3.3 \mathrm{mM} \mathrm{KCl}$ and in the nominal absence of $\mathrm{KCl}$. The ATPase activity of KdpFABC reconstituted in lipid vesicles was determined in the absence of detergent, which means that only the activity of the inside out oriented $\mathrm{KdpFABC}$ fraction was detected. The total amount of protein needed for a single measurement was on the order of $1 \mu \mathrm{g}$.

Reconstitution of the KdpFABC Complex in Lipid Vesicles. Reconstitution of the KdpFABC complex into vesicles was conducted as described previously. ${ }^{26,27}$ The $\mathrm{KdpFABC}$ complex was isolated and purified from membranes in $1 \%(\mathrm{w} / \mathrm{v}) \beta \mathrm{DDM}$ (instead of Aminoxide WS 35), purified in one step using a Ni NTA column, and suspended in $50 \mathrm{mM}$ Tris $\mathrm{HCl}$ ( $\mathrm{pH} 7.5$ ), $20 \mathrm{mM} \mathrm{MgCl}, 130 \mathrm{mM}$ imidazole, 150 $\mathrm{mM} \mathrm{NaCl}$, and $0.2 \%(\mathrm{w} / \mathrm{v}) \beta \mathrm{DDM}$. An appropriate amount of E. coli lipids (Avanti Polar Lipids, Alabaster, AL) was vacuum dried under rotation in a glass flask, and the resulting thin lipid film was dissolved with $2 \%(\mathrm{w} / \mathrm{v}) \beta \mathrm{DDM}$ and $2 \%(\mathrm{w} / \mathrm{v}) \mathrm{C}_{12} \mathrm{E}_{8}$ dialysis buffer containing $25 \mathrm{mM}$ imidazole, $1 \mathrm{mM}$ EDTA, 5 $\mathrm{mM} \mathrm{MgSO}$, and $70 \mathrm{mM} \mathrm{K} \mathrm{SO}_{4}(\mathrm{pH} \mathrm{7.2)}$. The final lipid concentration was $10 \mathrm{mg} / \mathrm{mL}$. The lipid/detergent mixture was sonicated for 3-5 min under a nitrogen atmosphere and kept at room temperature until a clear solution was obtained. Equal volumes of $2 \mathrm{mg} / \mathrm{mL}$ protein and $E$. coli lipid solution were mixed to obtain a protein:lipid ratio of $1: 5(\mathrm{w} / \mathrm{w})$, followed by the addition of $200 \mathrm{mg}$ of BioBeads SM 2 (Bio Rad), pretreated with dialysis buffer, per $600 \mu \mathrm{L}$ solution. During an overnight incubation at $4{ }^{\circ} \mathrm{C}$, the suspension was rotated $(40 \mathrm{rpm})$. The resulting vesicle suspension was finally separated from BioBeads with capillary tips (Biozym Scientific $\mathrm{GmbH}$ ) and stored for $3 \mathrm{~h}$ on ice before being used in fluorescence experiments. To determine the size distribution of the vesicles, dynamic light scattering measurements were performed at room temperature, using a DLS Viscotek 802 spectrometer. Their size was found to be $116 \pm 21 \mathrm{~nm}$. Vesicles were diluted to achieve a final concentration of approximately $0.1 \mathrm{mg}$ of lipid $/ \mathrm{mL}$ of buffer, filtered with a $0.45 \mu \mathrm{m}$ PVDF centrifugal filter (Millipore), and transferred to a $12 \mu \mathrm{L}$ square cuvette (Viscotek, 802DLS quartz cell). Distilled water and dialysis buffer were filtered with 0.02 $\mu \mathrm{m}$ inorganic membrane filters (Whatman). Intensity distribu tions of vesicle diameters were recorded and analyzed with Omnisize version 2.0.

RH421 Fluorescence Experiments. The steady state fluorescence measurements with detergent solubilized
KdpFABC were performed with a homemade setup using a HeNe laser (Laser 2000, Voltex, Inc., Colorado Springs, CO) with a wavelength of $594 \mathrm{~nm}$ to excite the fluorescence of the electrochromic styryl dye RH421. According to the physical mechanism of the styryl dye RH421 a decrease in fluorescence represents an uptake of positive charge inside the membrane domain of the protein under the chosen experimental conditions, whereby the decrease in fluorescence is linearly proportional to the amount of charge. ${ }^{17,18,22}$ The emitted light was collected at an angle perpendicular to the incident light, filtered by a narrow band interference filter $\left(\lambda_{\max }=663 \mathrm{~nm}\right.$; half width of $18 \mathrm{~nm}$ ), and detected by a photomultiplier (R2066, Hamamatsu Photonic, Hamamatsu, Japan). The photocurrent was amplified by a Keithley 427 current amplifier (Keithley Instruments, Cleveland, $\mathrm{OH}$ ) and the signal collected with a data acquisition board of a personal computer (PCI 7112, Imtec, Backnang, Germany) at a sampling frequency between 1 and $10 \mathrm{~Hz}$. The temperature of the cuvette was maintained by a thermostat at $20 \pm 0.5{ }^{\circ} \mathrm{C}$. The experiments were performed in buffer starting with $50 \mathrm{mM}$ Tris $\mathrm{HCl}$ and 2 $\mathrm{mM} \mathrm{MgCl}_{2}$ (pH 7.8). Subsequently, $200 \mathrm{nM} \mathrm{RH} 421$ and $9 \mu \mathrm{g} /$ $\mathrm{mL}$ detergent solubilized $\mathrm{KdpFABC}$ were added and allowed to equilibrate until a stable fluorescence signal, $F_{0}$, was obtained. Titrations were conducted by addition of small aliquots of the indicated substrates from various concentrated stock solutions until the signal had been saturated. Mg ATP and $\mathrm{Na}_{2}$ ATP were added from a buffered, $\mathrm{pH}$ adjusted solution diluted from a 0.5 $\mathrm{M}$ stock. To allow comparison between different titration experiments, normalized fluorescence changes with respect to the initial fluorescence level, $F_{0}$, were calculated according to the equation $\Delta F / F_{0}=\left(F-F_{0}\right) / F_{0}$. The substrate dependent fluorescence change, $F_{\text {norm }}$, was fit with a Hill function

$$
F_{\text {norm }}\left(\left[\mathrm{X}^{+}\right]\right)=F_{0}+\Delta F_{\max } /\left[1+\left(\left[\mathrm{X}^{+}\right] / K_{1 / 2}\right)^{-n}\right]
$$

where $\left[\mathrm{X}^{+}\right]$is the substrate ion concentration, $\Delta F_{\max }$ the maximal fluorescence change, $K_{1 / 2}$ the half saturating concen tration, and $n$ the Hill coefficient.

$\mathrm{DiSC}_{3}(5)$ Fluorescence Experiments. The $\mathrm{KdpFABC}$ complex is an electrogenic transport system. ${ }^{27,28}$ Thus, in vesicles, the inside out oriented ion pumps are activated by addition of ATP to the medium and generate an inside negative electric potential caused by the outward transport of $\mathrm{K}^{+}$. The positively charged fluorescent dye $\mathrm{DiSC}_{3}(5)$ was introduced as an indicator of inside negative membrane potentials in vesicles, and it has been shown to detect successfully the electrogenic pump activity of the reconstituted KdpFABC complex. ${ }^{27,29,30}$ To perform experiments, $1 \mathrm{~mL}$ of buffer containing $25 \mathrm{mM}$ imidazole, $1 \mathrm{mM}$ EDTA, $5 \mathrm{mM} \mathrm{MgSO}_{4}$, and various concentrations of $\mathrm{K}_{2} \mathrm{SO}_{4}(\mathrm{pH}$ 7.2) were thermally equilibrated in a cuvette. Sulfate salts have been chosen instead of chloride to minimize the leak conductance of the vesicle membrane; 300 $\mathrm{nM} \mathrm{DiSC} C_{3}(5)$ and an aliquot of vesicles corresponding to 80 $\mu \mathrm{g} / \mathrm{mL}$ lipid in the solution were added subsequently. The fluorescence was excited at $650 \mathrm{~nm}$ (5 nm slit), and the emission was detected at $675 \mathrm{~nm}$ (5 nm slit) in a Perkin Elmer LS 50B luminescence spectrometer. When a steady state fluorescence level was obtained, $2.5 \mathrm{mM} \mathrm{Mg} \mathrm{ATP} \mathrm{(} \mathrm{pH}$ adjusted) was added to trigger pump activity. The pump activity is reflected in a fluorescence decrease that exponentially approaches a steady state level at which the pump current is compensated by the leak current due to the membrane conductance. Subsequent addition of $1 \mu \mathrm{M}$ valinomycin, a $\mathrm{K}^{+}$ ionophore, caused a step change in fluorescence to a level 
indicating the Nernst potential determined by the actual $\mathrm{K}^{+}$ concentration inside and outside the vesicles. ${ }^{31}$ To allow a comparison between different experiments, the fluorescence changes were normalized with respect to the fluorescence level, $F_{0}$, at a membrane voltage of 0 , before the addition of ATP

$$
F_{\text {norm }}(t)=\frac{F(t)-F_{0}}{F_{0}}
$$

where $F_{\text {norm }}(t)$ is the normalized fluorescence amplitude and $F(t)$ the measured fluorescence. Calibration experiments using $1 \mu \mathrm{M}$ valinomycin, $140 \mathrm{mM} \mathrm{K} \mathrm{K}^{+}$inside the vesicles, and various external $\mathrm{K}^{+}$concentrations showed a linear dependence of membrane potential and fluorescence change with $0.17 \% / \mathrm{mV}$ (not shown).

\section{RESULTS}

$\mathrm{KdpFABC}$ was expressed as described in Materials and Methods, isolated, and purified with six different detergents, Fos choline $12, \beta$ DDM, $\beta$ DM, PCC $\alpha \mathrm{M}^{32}$ LAPAO, and Aminoxide WS 35. Via this approach, the detergents were tested with respect to their ability to preserve the functional integrity of the solubilized KdpFABC complexes. The effects of the detergents on characteristic properties of the ion pump are compiled in Table 1 . The enzyme activity, $E_{A}$, was determined

Table 1. Effects of Various Detergents Used To Solubilize the KdpFABC Complex ${ }^{a}$

\begin{tabular}{|c|c|c|c|}
\hline detergent & $E_{\mathrm{A}}\left(\mu \mathrm{mol} \mathrm{mg} \mathrm{min}^{-1}\right)$ & $F_{\text {ind }}$ & $K_{1 / 2}\left(\mathrm{~K}^{+}\right)(\mathrm{mM})$ \\
\hline Fos-choline 12 & $0.102 \pm 0.024$ & 1.2 & 14.95 \\
\hline$\beta$-DDM & $0.534 \pm 0.001$ & 2.1 & 3.340 \\
\hline$\beta$-DM & $0.554 \pm 0.027$ & 2.2 & 1.30 \\
\hline PCC- $\alpha-\mathrm{M}$ & $0.275 \pm 0.013$ & 2.6 & 0.16 \\
\hline LAPAO & $0.628 \pm 0.032$ & 2.2 & 0.13 \\
\hline Aminoxide WS- $35^{b}$ & $0.868 \pm 0.021$ & 4.0 & 0.00655 \\
\hline
\end{tabular}

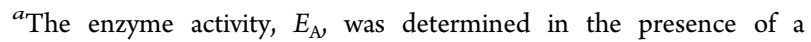
saturating concentration of $\mathrm{K}^{+}$. The induction, $F_{\text {ind }}$ indicates the factor by which $E_{\mathrm{A}}$ increased when the $\mathrm{K}^{+}$concentration was increased from nominally 0 to a saturating level of $3.3 \mathrm{mM} . K_{1 / 2}\left(\mathrm{~K}^{+}\right)$was determined by equilibrium titration experiments with $\mathrm{RH} 421$ and represents the $\mathrm{K}^{+}$concentration at which $\mathrm{K}^{+}$binding was half maximal. ${ }^{b}$ Uncharac terized mixture of detergents with LAPAO as the major component.

at $37{ }^{\circ} \mathrm{C}$ in the nominal absence of $\mathrm{KCl}$ and at a saturating concentration of $\mathrm{KCl}(3.3 \mathrm{mM})$. The ratio between both activities is the induction factor, $F_{\text {ind }}$. In addition, the half saturating $\mathrm{K}^{+}$concentration was obtained by $\mathrm{K}^{+}$binding studies with RH421 (see below). In the solubilized KdpFABC complexes, a correlation was found between the maximal enzyme activity and $\mathrm{K}^{+}$binding affinity. Only one detergent, Aminoxide WS 35, yielded solubilized protein complexes with high enzyme activity and a high $\mathrm{K}^{+}$binding affinity $\left(K_{1 / 2}=6.5\right.$ $\mu \mathrm{M})$ comparable to the affinity found under physiological conditions. ${ }^{5,33}$ Solubilization with Aminoxide WS 35 yielded an enzyme with a $\mathrm{K}^{+}$binding affinity that is much closer to that of the physiological state than when it is solubilized in LAPAO, the major component of WS 35. This observation indicates that the protein needs specific but so far unidentified component(s) of the detergent mixture to stabilize a properly functioning complex that maintains the $\mathrm{K}^{+}$binding sites in a state close to that in the physiological membrane environment. Therefore, all subsequent experiments were performed with protein com plexes solubilized in Aminoxide WS 35.
Substrate Dependence of Enzyme Activity. The enzyme activity of the KdpFABC complex solubilized in Aminoxide WS 35 was determined for $\mathrm{K}^{+}$concentrations up to $3.3 \mathrm{mM}$ at $\mathrm{pH} 7.8$ (Figure $2 \mathrm{~A}$ ) and in a $\mathrm{pH}$ range between 5.5
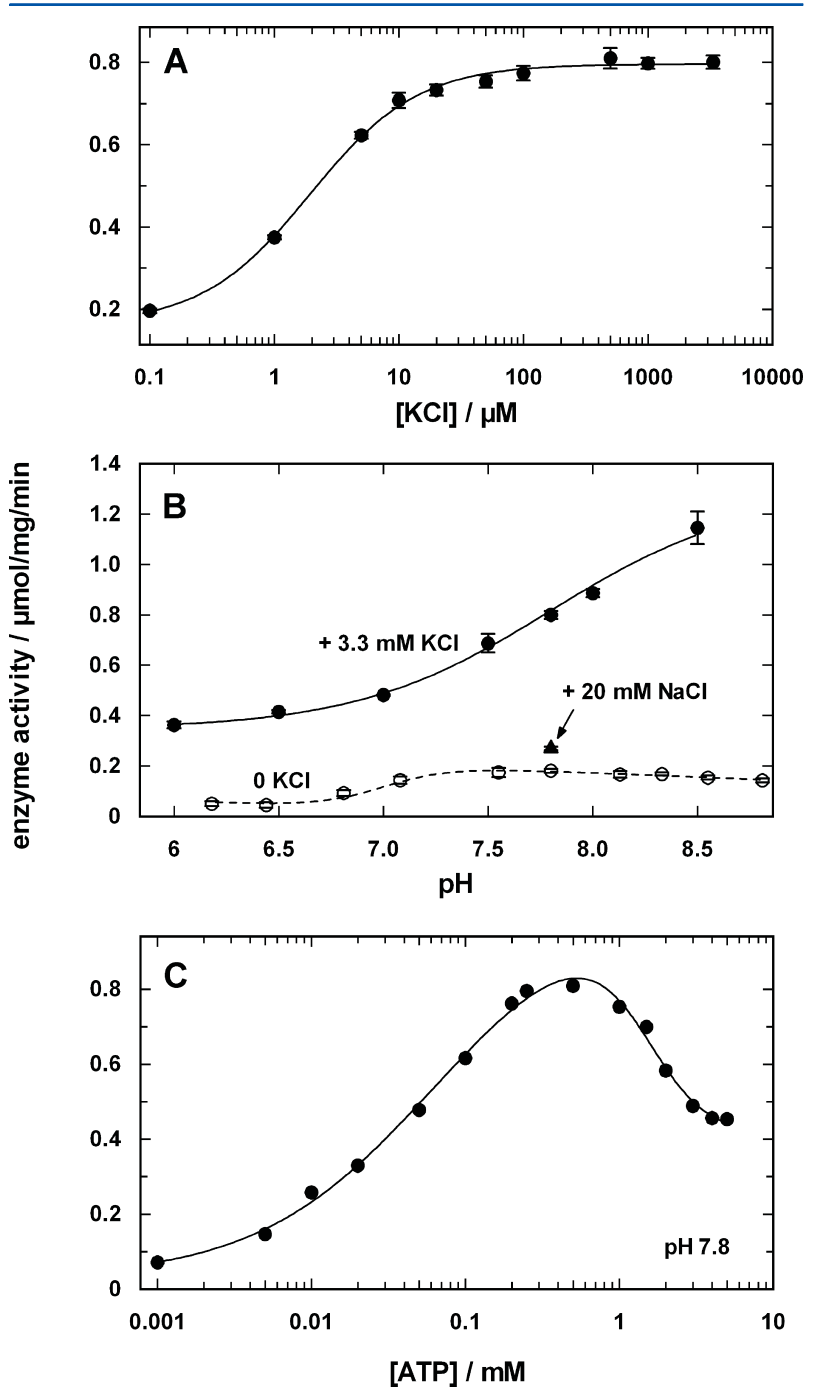

Figure 2. $\mathrm{pH}, \mathrm{K}^{+}$, and ATP concentration dependence of the enzyme activity of the solubilized $\mathrm{KdpFABC}$ complex in the presence of a saturating level of $\mathrm{KCl}$. (A) The $\mathrm{K}^{+}$dependence of enzyme activity could be fit by a simple binding isotherm with a $K_{\mathrm{m}}$ of $2.03 \pm 0.12 \mu \mathrm{M}$. (B) Enzyme activity plotted in the presence $(\bullet)$ or absence $(O)$ of $\mathrm{K}^{+}$ in the presence of $20 \mathrm{mM} \mathrm{NaCl}(\mathrm{pH} \mathrm{7.8)}(\boldsymbol{\Delta})$. The data were fit with a simple binding isotherm (-) with a $\mathrm{pK}$ of 7.8. (C) ATP dependence of the KdpFABC activity at $\mathrm{pH}$ 7.8. The enzyme activity was fit by the sum of two Hill functions with a $K_{1 / 2,1}$ of $65 \pm 18 \mu \mathrm{M}$ and a $K_{1 / 2,2}$ of $1.54 \pm 0.13 \mathrm{mM}$.

and 8.5 in the presence of a saturating level of $\mathrm{KCl}(3.3 \mathrm{mM})$ (Figure $2 \mathrm{~B}$ ). The $\mathrm{K}^{+}$concentration dependence and the $\mathrm{pH}$ dependence could both be fit with simple Michaelis-Menten kinetics. The $K_{\mathrm{M}}$ value of $\mathrm{K}^{+}$induced enzyme activity was determined to be $2.03 \pm 0.12 \mu \mathrm{M}$ at $\mathrm{pH}$ 7.8. For the $\mathrm{pH}$ dependence of the enzyme activity, a $\mathrm{pK}$ of 7.8 was found at a saturating concentration of $\mathrm{K}^{+}$(Figure 2B). The $\mathrm{pH}$ depend ence reveals that proton binding reduces the enzyme activity. According to the fitting parameters, a factor of $\sim 3$ could be 
determined between the deprotonated and protonated states of the enzyme. Increased $\mathrm{H}^{+}$concentrations reduce the turnover number of the KdpFABC complex. This effect may be produced by binding of an allosteric proton to the $\mathrm{KdpB}$ subunit affecting the enzyme activity and/or by a competition at the ion binding sites between the transported $\mathrm{K}^{+}$ions and protons in the KdpA subunit. If the competing $\mathrm{H}^{+}$binds to an ion binding site and would be transported as a counterion, as in the case of the H,K ATPase, one would expect the overall activity of the ion pump to decrease at high $\mathrm{pH}$ because of the lack of a transport substrate. This is not the case.

In the absence of $\mathrm{K}^{+}$, nonetheless, a $\mathrm{pH}$ dependence of enzyme activity was found with an overall lower activity profile and a maximal activity of $0.18 \pm 0.02 \mu \mathrm{mol}(\mathrm{mg} \text { of protein })^{-1}$ $\mathrm{min}^{-1}$ at $\mathrm{pH} 7.5 \pm 0.2$ (Figure $2 \mathrm{~B}$ ). A decrease in activity was observed at lower $\mathrm{pH}$, possibly caused by an allosteric effect. At higher $\mathrm{pH}(>7.8)$, enzyme activity decreased only slightly to $\sim 0.14 \mu \mathrm{mol}(\mathrm{mg} \text { of protein })^{-1} \mathrm{~min}^{-1}$ at $\mathrm{pH} 8.8$. Because the activity increases in this $\mathrm{pH}$ range when $\mathrm{K}^{+}$is present, it can be proposed that the reduction in the absence of $\mathrm{K}^{+}$is caused by a weaker binding of protons. In summary, these findings are compatible with the interpretation that the ion pump is able to transport protons as well in the absence of $\mathrm{K}^{+}$ions, however, to a much lesser extent. To make sure that the residual enzyme activity was not produced by contamination with $\mathrm{K}^{+}$in the doubly distilled water, a series of experiments was performed in buffer prepared with ultrapure water, but no significant difference in enzyme activity could be detected (data not shown). In the absence of $\mathrm{K}^{+}$, the enzyme activity was determined to be correspondingly $0.17 \pm 0.01 \mu \mathrm{mol}(\mathrm{mg}$ of protein $)^{-1} \mathrm{~min}^{-1}$ at $\mathrm{pH} 7.8$ in ultrapure water.

In the presence of $20 \mathrm{mM} \mathrm{NaCl}$ (suprapur quality), a small increase in enzyme activity to $0.27 \pm 0.01 \mu \mathrm{mol}(\mathrm{mg}$ of protein $)^{-1} \min ^{-1}$ was found at $\mathrm{pH}$ 7.8. This observation indicates that in the absence of $\mathrm{K}^{+}$also $\mathrm{Na}^{+}$may replace $\mathrm{K}^{+}$to at least a minor extent.

The ATP concentration dependence was analyzed to estimate the binding affinity for ATP. The $\mathrm{Na}_{2}$ ATP concentration was varied between $1 \mu \mathrm{M}$ and $5 \mathrm{mM}$, whereas the $\mathrm{pH}$ was kept at $7.8 \pm 0.1$. In the range up to $500 \mu \mathrm{M}$, the enzyme activity increased with ATP concentration. At higher concentrations, a decrease was observed (Figure 2C). The data were fit with a sum of two Hill functions (cf. eq 1). For the increasing phase, a $K_{1 / 2,1}$ of $65 \pm 18 \mu \mathrm{M}(n=0.9)$ could be determined, and for the decreasing phase, a $K_{1 / 2,2}$ of $1.54 \pm$ $0.13 \mathrm{mM}(n=2.1)$ was obtained. To exclude effects of the traces of $\mathrm{Na}^{+}$, experiments were repeated with $\mathrm{Mg}$ ATP, and the same behavior with almost identical $K_{1 / 2}$ values was observed (data not shown).

To further elucidate the possible roles of the proton, experiments were performed to specifically target competition of $\mathrm{H}^{+}$with $\mathrm{K}^{+}$in the $\mathrm{E}_{1}$ and $\mathrm{P} \mathrm{E}_{2}$ conformations of the ion pump. In the absence of ATP or $\mathrm{P}_{\mathrm{i}}$, the KdpFABC complex is in the $\mathrm{E}_{1}$ conformation.

RH421 Standard Experiments. The so called standard experiment, as described here, can be used to characterize the electrogenic ion binding properties of the ion pumps in the two conformational states, $\mathrm{E}_{1}$ and $\mathrm{P}_{2}$, and at different buffer $\mathrm{pH}$ values. A cuvette with $2 \mathrm{~mL}$ of buffer [ $50 \mathrm{mM}$ Tris $\mathrm{HCl}$ and 2 $\mathrm{mM} \mathrm{MgCl} 2$ ( $\mathrm{pH} 7.8$ )] was thermally equilibrated, before 200 $\mathrm{nM} \mathrm{RH} 421$ and $9 \mu \mathrm{g} / \mathrm{mL}$ detergent solubilized KdpFABC were added. After a stable fluorescence signal had been achieved, aliquots of $\mathrm{HCI}$ were added to obtain the desired $\mathrm{pH}$, followed by the addition of (saturating) $1 \mathrm{mM} \mathrm{ATP}$ and $250 \mu \mathrm{M} \mathrm{KCl}$ (Figure 3). Addition of $\mathrm{H}^{+}, \mathrm{K}^{+}$, and, to a very minor extent,
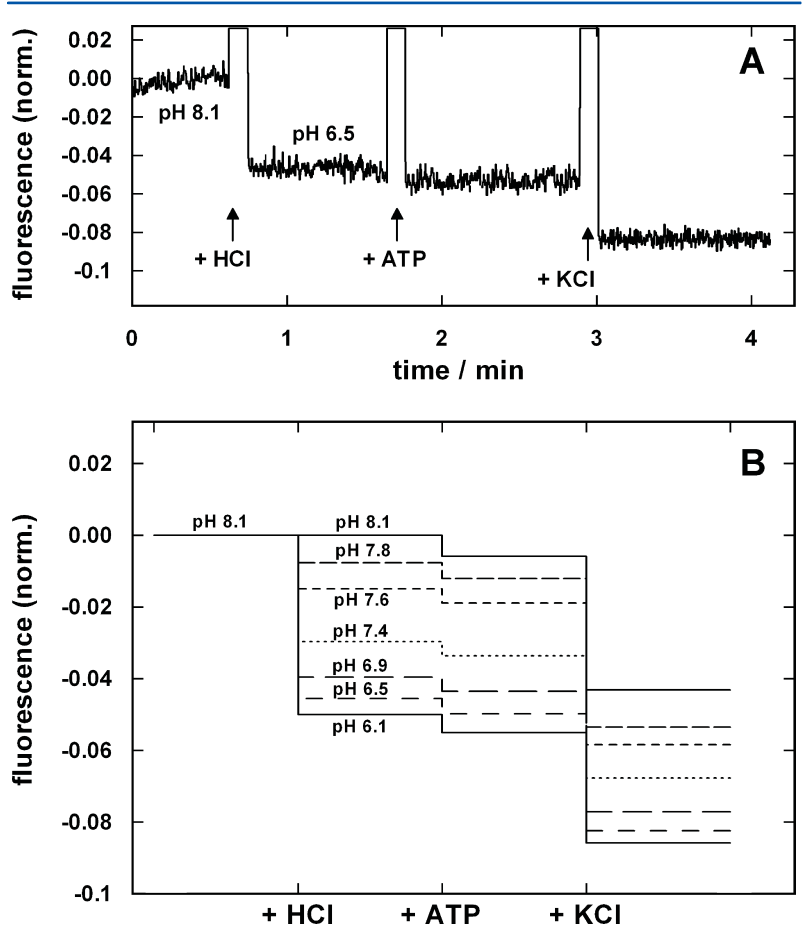

Figure 3. RH421 standard experiment that reveals the electrogenic contributions of additions of substrate to the isolated, solubilized KdpFABC complex. (A) Fluorescence trace induced by the sequential addition of $\mathrm{HCl}$ to yield a $\mathrm{pH}$ of $6.5(6.5 \mu \mathrm{L}$ of $\mathrm{HCl}, 4 \mathrm{M}), 1 \mathrm{mM}$ ATP, and $250 \mu \mathrm{M} \mathrm{KCl}$. (B) Schematic representation of the fluorescence changes detected after addition of various amounts of $\mathrm{HCl}$ to yield the indicated $\mathrm{pH}$. Concentrations of ATP and $\mathrm{KCl}$ were as in panel $\mathrm{A}$.

ATP generated a fluorescence decrease. To check whether there is a mutual effect on the binding behavior, in a second set of experiments the order of ATP and $\mathrm{HCl}$ addition was reversed without any effect on the substrate induced fluorescence decreases (not shown). In the absence of ATP, the $\mathrm{KdpFABC}$ complex is stabilized in its $\mathrm{E}_{1}$ conformation, and binding of $\mathrm{K}^{+}$, and possibly $\mathrm{H}^{+}$, is assumed to take place from the cytoplasmic side. After addition of $1 \mathrm{mM}$ ATP, the enzyme proceeds into the $\mathrm{PE}_{2}$ conformation in which ion binding is assumed to take place from the extracellular side. Correspond ing experiments were performed to study the electrogenicity of ion binding in the unphosphorylated state, after phosphor ylation by ATP, and after the so called backdoor phosphor ylation triggered by the addition of $1 \mathrm{mM}$ Tris phosphate $\left(\mathrm{P}_{\mathrm{i}}\right)$, which reverses the direction of reaction steps in the PostAlbers cycle $\left(E_{1}+P_{i} \rightarrow E_{2} P\right)$. The evaluation of the results obtained from all standard experiments is shown in Figure 4.

The substrate induced decreases in RH421 fluorescence (Figures 3 and 4 ) indicate that binding of both ion species, $\mathrm{K}^{+}$ and $\mathrm{H}^{+}$, is an electrogenic process in the unphosphorylated and phosphorylated form of the $\mathrm{KdpFABC}$ complex; i.e., the ions are bound to sites located in a protein domain inside the membrane dielectric. From Figure 4A, it can be seen that phosphorylation of the enzyme by ATP as well as by $\mathrm{P}_{\mathrm{i}}$ produced only a very small fluorescence change $(<0.5 \%)$, which implies that no significant charge movements occur in 


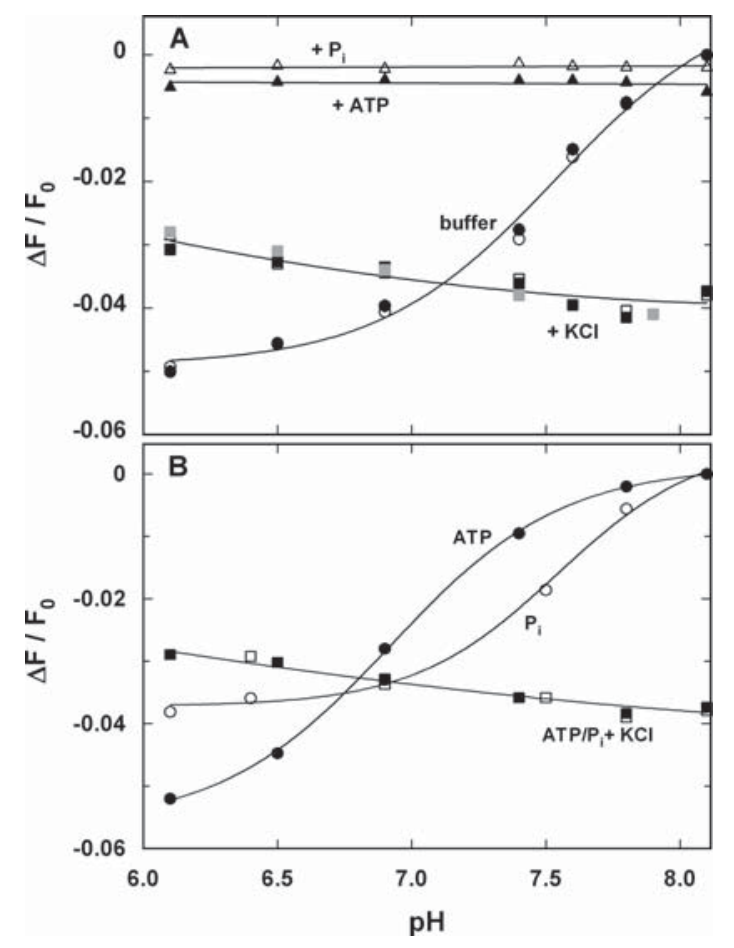

Figure 4. Analysis of the electrogenicity of binding of substrate to the isolated, solubilized $\mathrm{KdpFABC}$ complex. (A) $\mathrm{pH}$ dependence of the RH421 fluorescence changes induced by the sequential additions of aliquots of $\mathrm{HCl}, 1 \mathrm{mM}$ ATP or $\mathrm{P}_{\mathrm{i}}$, and $250 \mu \mathrm{M} \mathrm{KCl}$ (cf. Figure 3B): (filled symbols) experiments with additions of ATP, (empty symbols) experiments with addition of $\mathrm{P}_{\mathrm{i}}$, and (gray squares) $\mathrm{K}^{+}$addition in $\mathrm{E}_{1}$. (B) $\mathrm{pH}$ dependence of the fluorescence changes induced by the inverted sequential additions of $1 \mathrm{mM}$ ATP or $\mathrm{P}_{\mathrm{i}}$ first, then appropriate aliquots of $\mathrm{HCl}$, and finally $250 \mu \mathrm{M} \mathrm{KCl}$. The lines are drawn to guide the eye.

the corresponding enzymatic reaction steps. Furthermore, it was found that the $\mathrm{pH}$ affects the amount of electrochemically bound $\mathrm{K}^{+}$. The $\mathrm{H}^{+}$binding kinetics in the unphosphorylated state differ from those following phosphorylation by ATP or $\mathrm{P}_{\mathrm{i}}$ (Figure 4B). In contrast, the fluorescence decrease upon $\mathrm{K}^{+}$ binding and its $\mathrm{pH}$ dependence were similar in the unphosphorylated state and both phosphorylated states (Figure $4 A, B)$. These effects will be analyzed in detail in the next paragraph.

Ion Binding Titrations. Both cation species, $\mathrm{K}^{+}$and $\mathrm{H}^{+}$, were tested with respect to their binding affinity for the KdpFABC complex. With a buffer containing $50 \mathrm{mM}$ Tris $\mathrm{HCl}$, $2 \mathrm{mM} \mathrm{MgCl}_{2}$ (pH 7.8), $200 \mathrm{nM} \mathrm{RH} 421$, and $9 \mu \mathrm{g} / \mathrm{mL}$ protein as a starting point, the saturating addition of $\mathrm{KCl}$ or $\mathrm{HCl}$ produced a fluorescence decrease of up to $\sim 5 \%$ (Figure 4 ). When $\mathrm{KCl}$ (or $\mathrm{HCl}$ ) is added in appropriately small aliquots, the occupation of the binding site(s) can be titrated and the half saturating $\mathrm{K}^{+}$concentration, $K_{1 / 2}$ (or $\mathrm{pK}$ in case of $\mathrm{H}^{+}$ additions), can be determined (Figures 5 and 6). To obtain this kinetic parameter, we monitored the RH421 fluorescence changes upon addition of small aliquots of $\mathrm{KCl}$ until a saturating level was obtained. The normalized fluorescence levels were plotted versus $\mathrm{K}^{+}$concentration (or $\mathrm{pH}$ ). All titration experiments were performed at least three times, and the average values were analyzed.
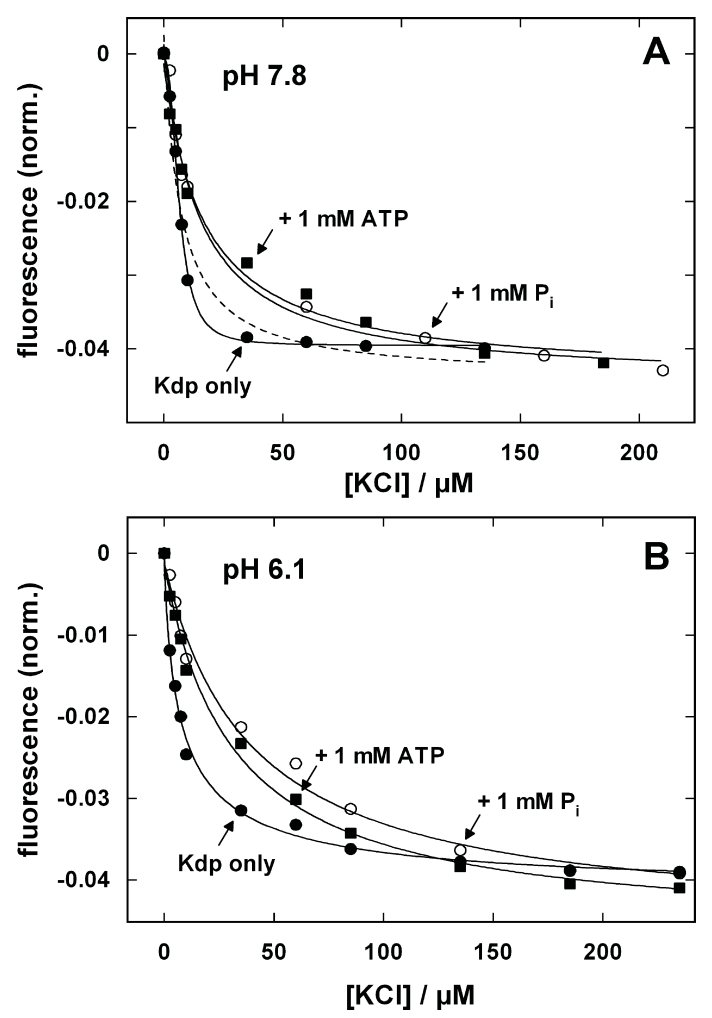

Figure 5. Electrogenic binding of $\mathrm{K}^{+}$ions as detected by $\mathrm{RH} 421$ fluorescence in buffer containing $50 \mathrm{mM}$ Tris $\mathrm{HCl}$ and $2 \mathrm{mM} \mathrm{MgCl}_{2}$ (pH 7.8) in the absence or presence of $1 \mathrm{mM}$ ATP or $1 \mathrm{mM}$ inorganic phosphate $\left(\mathrm{P}_{\mathrm{i}}\right)$. (A) $\mathrm{K}^{+}$titrations at $\mathrm{pH} 7.8$ fit with half saturating concentrations, $K_{1 / 2}$, of $6.5 \mu \mathrm{M}$ (Kdp only), $14.4 \mu \mathrm{M}\left(\mathrm{P}_{\mathrm{i}}\right)$, and 16.8 $\mu \mathrm{M}$ (ATP). (B) $\mathrm{K}^{+}$titrations at $\mathrm{pH}$ 6.1. The half saturating concentrations, $K_{1 / 2}$, were determined to be $8.3 \pm 0.4 \mu \mathrm{M}$ (Kdp only), $37.9 \pm 7.3 \mu \mathrm{M}\left(\mathrm{P}_{\mathrm{i}}\right)$, and $31.6 \pm 1.0 \mu \mathrm{M}$ (ATP). The lines drawn through the data were fits with either the Hill function or a MichaelisMenten binding isotherm (see the text).

Results of the $\mathrm{K}^{+}$titration experiments are shown in Figure 5. First, titrations were performed in buffer containing $50 \mathrm{mM}$ Tris $\mathrm{HCl}, 2 \mathrm{mM} \mathrm{MgCl}(\mathrm{pH} 7.8$ ), and $9 \mu \mathrm{g} / \mathrm{mL}$ protein, a condition under which $\mathrm{KdpFABC}$ adopts the $\mathrm{E}_{1}$ conformation according to the Post-Albers cycle. When the concentration dependence was fit with simple Michaelis-Menten kinetics, no satisfactory fit could be obtained (dashed line; $K_{1 / 2}=6.9 \pm 2.1$ $\mu \mathrm{M}$ ). A fit with the Hill function (eq 1 ) resulted in a half saturating concentration, $K_{1 / 2}$, of $6.5 \pm 0.3 \mu \mathrm{M} \mathrm{K}^{+}$and a Hill coefficient, $n$, of $2.3 \pm 0.3$ (solid line). $n \geq 2$ indicates a cooperative binding of more than one $\mathrm{K}^{+}$. In a second set of experiments, $1 \mathrm{mM} \mathrm{Mg} \mathrm{ATP} \mathrm{was} \mathrm{added} \mathrm{before} \mathrm{the} \mathrm{KCl}$ titration to convert the enzyme preferentially into its $\mathrm{P} \mathrm{E}_{2}$ conformation. In this case, the concentration dependence could be fit with simple Michaelis-Menten kinetics, and the $K_{1 / 2}$ value was found to be $16.8 \pm 3.0 \mu \mathrm{M}$. In the presence of $\mathrm{KCl}$ and ATP, however, a substrate condition is established in which the pump works in its turnover mode, and so far, it is not clear whether the enzyme is present predominantly in the $\mathrm{PE}_{2}$ conformation under these conditions. Therefore, a third set of experiments was performed in the presence of $1 \mathrm{mM}$ inorganic phosphate, $\mathrm{P}_{\mathrm{i}}$, instead of $\mathrm{Mg}$ ATP. Under this condition, $\mathrm{P}$ type ATPases are known to perform a backdoor phosphorylation, and the pumps are trapped in a $\mathrm{PE}_{2}$ state. $^{34}$ In these 

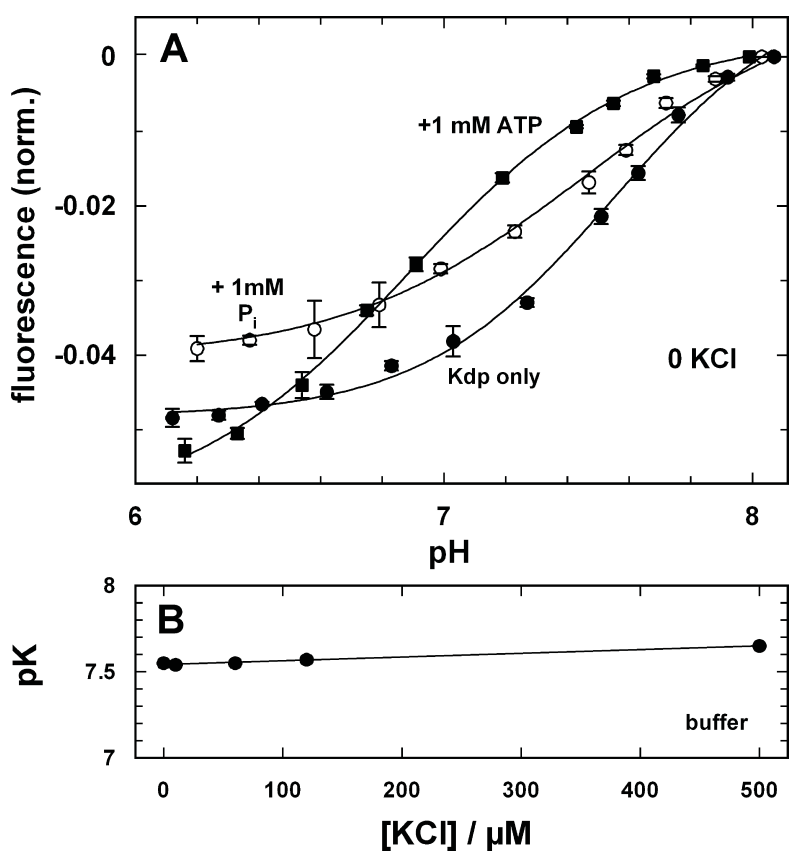

Figure 6. $\mathrm{pH}$ titration of $\mathrm{RH} 421$ fluorescence with the solubilized $\mathrm{KdpFABC}$ complex in different conformations in the absence of $\mathrm{K}^{+}$. (A) In the $\mathrm{E}_{1}$ conformation ( $\mathrm{Kdp}$ only), a $\mathrm{pK}$ of 7.6 could be determined, whereas in $\mathrm{P} \mathrm{E}_{2}, \mathrm{pK}$ values of $6.8(+1 \mathrm{mM}$ ATP) and 7.1 $\left(+1 \mathrm{mM} \mathrm{P}_{\mathrm{i}}\right)$ were determined. The lines drawn represent fits with the Hill function. (B) Distribution of $\mathrm{p} K$ values obtained in corresponding $\mathrm{pH}$ titrations in the presence of different $\mathrm{K}^{+}$concentrations. The $\mathrm{pK}$ increased only slightly from $7.55(0 \mathrm{KCl})$ to $7.65(500 \mu \mathrm{M} \mathrm{KCl})$.

experiments, a $K_{1 / 2}$ of $14.4 \pm 2.6 \mu \mathrm{M}$ was obtained by fitting with the Michaelis-Menten kinetics [Figure 5A (O)]. Because the data of $\mathrm{Mg} \mathrm{ATP}$ and $\mathrm{P}_{\mathrm{i}}$ are virtually identical, there is no significant difference expected in the $\mathrm{K}^{+}$binding kinetics of both phosphorylation methods, and thus, it can be assumed that the enzyme complex adopts preferentially the $\mathrm{P} \mathrm{E}_{2}$ conformation in both experiments. The apparent $\mathrm{K}^{+}$binding affinity was, however, decreased by a factor of 2 with respect to the unphosphorylated state $\left(\mathrm{E}_{1}\right)$. It has to be kept in mind that in all three titration experiments the maximal fluorescence decrease was nearly identical $(\sim 0.04)$; i.e., the same number of $\mathrm{K}^{+}$ions is bound inside the membrane domain of the KdpFABC complex.

The potassium titration experiments were repeated at $\mathrm{pH} 6.1$ by addition of $\mathrm{HCl}$ to test the effect of additionally bound $\mathrm{H}^{+}$ (Figure 5B). In this case, all three data sets could be fit with simple Michaelis-Menten kinetics. In the $\mathrm{E}_{1}$ conformation of the pump (buffer without ATP and $\mathrm{P}_{\mathrm{i}}$ ), the $K_{1 / 2}$ value was slightly increased to $8.3 \pm 0.4 \mu \mathrm{M}$. In contrast, in the $\mathrm{P} \mathrm{E}_{2}$ conformation, the $K_{1 / 2}$ values were significantly increased: 31.6 $\pm 1.0 \mu \mathrm{M}(\mathrm{ATP})$ and $37.9 \pm 7.3 \mu \mathrm{M}\left(\mathrm{P}_{\mathrm{i}}\right)$. The presence of a higher $\mathrm{H}^{+}$concentration reduced the apparent $\mathrm{K}^{+}$binding affinity. In the unphosphorylated state, the half saturating $\mathrm{K}^{+}$ concentration increased to an only minor extent when $\mathrm{pH}$ was reduced from 7.8 to 6.1. In the phosphorylated state with either ATP or $\mathrm{P}_{\mathrm{i}}$, the $\mathrm{pH}$ effect was much more pronounced, and $K_{1 / 2}$ approximately doubled in both phosphorylated states (Table 2).

To investigate the effect of protons in the pumping cycle, proton titration experiments were conducted (Figure 6). The buffer was initially adjusted to $\mathrm{pH} 8.0-8.1$, and aliquots of $\mathrm{HCl}$
Table 2. Comparison of Ion Binding Properties of Detergent Solubilized KdpFABC ${ }^{a}$

$\begin{array}{llccc} & & \text { Kdp only } & \text { with } 1 \mathrm{mM} \text { ATP } & \text { with } 1 \mathrm{mM} \mathrm{P} \text { i } \\ K_{1 / 2}(\mu \mathrm{M}) & \mathrm{pH} 7.8 & 6.5 \pm 0.3 & 16.8 \pm 3.0 & 14.4 \pm 2.6 \\ & \mathrm{pH} 6.1 & 8.3 \pm 0.4 & 31.6 \pm 1.0 & 37.9 \pm 7.3 \\ \mathrm{pK} & 0 \mathrm{~K}^{+} & 7.6 \pm 0.1 & 6.8 \pm 0.1 & 7.1 \pm 0.1 \\ & 500 \mu \mathrm{M} \mathrm{K}^{+} & 7.7 \pm 0.2 & 5.7 \pm 0.3 & 7.2 \pm 0.2\end{array}$

${ }^{a} \mathrm{Half}$ saturating $\mathrm{K}^{+}$concentrations were determined at $\mathrm{pH} 7.8$ and 6.1 for both the unphosphorylated and phosphorylated state induced by the addition of Mg ATP or inorganic phosphate $\left(\mathrm{P}_{\mathrm{i}}\right)$. Apparent $\mathrm{pK}$ values were obtained in the absence and presence of $500 \mu \mathrm{M} \mathrm{KCl}$. The given values are the means of at least three experiments, and errors are standard errors of the mean.

were added until a $\mathrm{pH}$ of 6.1 was reached. The relative fluorescence changes upon ion titration were recorded, and the $\mathrm{p} K$ values for proton binding were determined by fitting the data with the Hill function. Figure $6 \mathrm{~A}$ shows $\mathrm{pH}$ titration experiments in buffer containing $50 \mathrm{mM}$ Tris $\mathrm{HCl}, 2 \mathrm{mM}$ $\mathrm{MgCl}_{2}, 200 \mathrm{nM} \mathrm{RH} 421$, and $9 \mu \mathrm{g} / \mathrm{mL} \mathrm{KdpFABC}(0 \mathrm{KCl})$, with and without $1 \mathrm{mM} \mathrm{Mg} \mathrm{ATP} \mathrm{or} 1 \mathrm{mM}$ inorganic phosphate. The $\mathrm{pH}$ dependence could be fit only with the Hill function and Hill coefficients of $>1.4$. Determined $\mathrm{pK}$ values were $7.6 \pm$ 0.1 (Kdp only), $6.8 \pm 0.1$ (with ATP), and $7.1 \pm 0.1$ (with $\mathrm{P}_{\mathrm{i}}$ ). Varying $\mathrm{KCl}$ concentrations had no significant effect on the $\mathrm{pK}$ value. Figure $6 \mathrm{~B}$ shows the dependence of $\mathrm{pK}$ on $\mathrm{KCl}$ concentration up to $500 \mu \mathrm{M}$ in the unphosphorylated state of $\mathrm{KdpFABC}$. Were $\mathrm{K}^{+}$to compete with $\mathrm{H}^{+}$binding, the apparent $\mathrm{pK}$ would decrease with increasing $\mathrm{KCl}$ concentrations. The $\mathrm{pK}$ was, however, still $7.7 \pm 0.2$ at $500 \mu \mathrm{M} \mathrm{KCl}$. The fluorescence decrease at the lowest $\mathrm{pH}$ tested $(\sim 6)$ was independent of the $\mathrm{K}^{+}$concentration up to $120 \mu \mathrm{M}$, where $\Delta F_{\max }(\mathrm{pH} 6)=-0.057$ \pm 0.002 (not shown). At $500 \mu \mathrm{M} \mathrm{K}^{+}$, an only slight increase to $-0.050 \pm 0.01$ was found.

The results revealing mutual interference of $\mathrm{K}^{+}$and $\mathrm{H}^{+}$ binding are shown in Table 2. From these data, it is apparent that the $\mathrm{K}^{+}$binding affinity in the phosphorylated state is generally lower than in the $\mathrm{E}_{1}$ conformation. A lower $\mathrm{pH}$ reduces the $\mathrm{K}^{+}$binding affinity, more strongly in the phosphorylated state (by ATP or $\mathrm{P}_{\mathrm{i}}$ ). In contrast, the effect of $\mathrm{K}^{+}$on the binding of $\mathrm{H}^{+}$is much less pronounced. There are only minor differences in $\mathrm{pK}$ in the absence and presence of $500 \mu \mathrm{M} \mathrm{KCl}$ under all three conditions tested. This asymmetry is remarkable, as well as the difference in $\mathrm{pK}$ between the phosphorylated states caused by either ATP or $\mathrm{P}_{\mathrm{i}}$. To obtain additional information about the competition between $\mathrm{K}^{+}$and $\mathrm{H}^{+}$in the $\mathrm{E}_{1}$ conformation, the $\mathrm{K}^{+}$binding kinetics were analyzed in terms of a Lineweaver-Burk plot. The steady state $\mathrm{K}^{+}$binding can be represented by the $\mathrm{RH} 421$ fluorescence decrease relative to the level in the absence of $\mathrm{K}^{+}$. Titrations at five different $\mathrm{pH}$ values in the range of 7.8-6.1 are shown in Figure 7 . The intersection of the linear lines through the data points is above the $1 /\left[\mathrm{K}^{+}\right]$axis and thus indicates a mixed inhibition of $\mathrm{K}^{+}$binding by $\mathrm{H}^{+}$; i.e., at least two different mechanisms contribute to the inhibitory effect.

To test whether $\mathrm{Na}^{+}$ions are able to replace $\mathrm{K}^{+}$ions in the binding sites, corresponding $\mathrm{Na}^{+}$titrations were conducted (data not shown). The concentration dependence could be fit with simple Michaelis-Menten kinetics with a $K_{1 / 2}$ of $4.3 \pm 0.2$ $\mathrm{mM}$ and the same maximal fluorescence decrease of $-4.2 \%$ as in the case of $\mathrm{K}^{+}$. This indicates that the same amount of charge 


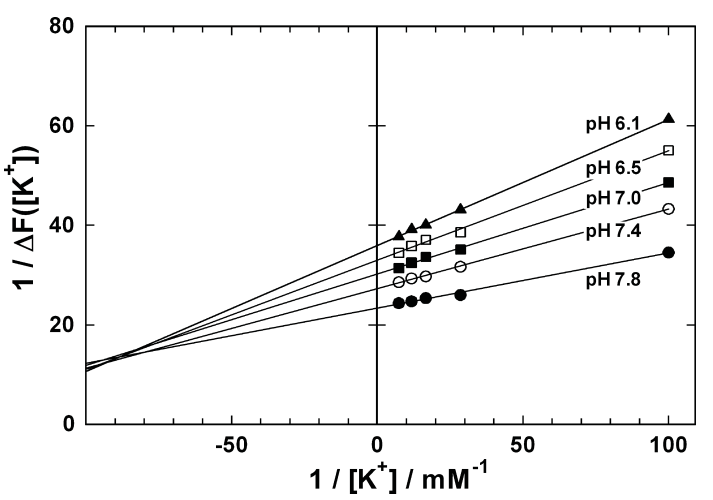

Figure 7. Lineweaver-Burk plot of $\mathrm{K}^{+}$binding to solubilized $\mathrm{KdpFABC}$ at different $\mathrm{pH}$ values. The intersection of the regression lines through the data points above the $1 /\left[\mathrm{K}^{+}\right]$axis indicates a mixed inhibition of $\mathrm{K}^{+}$binding by $\mathrm{H}^{+}$.

enters the binding sites but the binding affinity is $\sim 660$ fold lower.

In the case of the $\mathrm{Na}, \mathrm{K}$ ATPase, it was reported that the $\mathrm{Na}^{+}$ binding affinity is reduced by increasing $\mathrm{Mg}^{2+}$ concentrations. ${ }^{35}$ To examine a similar effect in $\mathrm{K}^{+}$binding of $\mathrm{KdpFABC}, \mathrm{KCl}$ titrations similar to those depicted in Figure 5 were performed at $\mathrm{pH} 7.8$ in the presence of various $\mathrm{Mg}^{2+}$ concentrations. The $\mathrm{K}^{+}$concentration dependence was fit with the Hill function (eq 1 ), and the respective half saturating $\mathrm{K}^{+}$concentrations, $K_{1 / 2}$, and the maximal fluorescence change, $\Delta F$, were plotted against the $\mathrm{Mg}^{2+}$ concentration (Figure 8). Similar to what was found

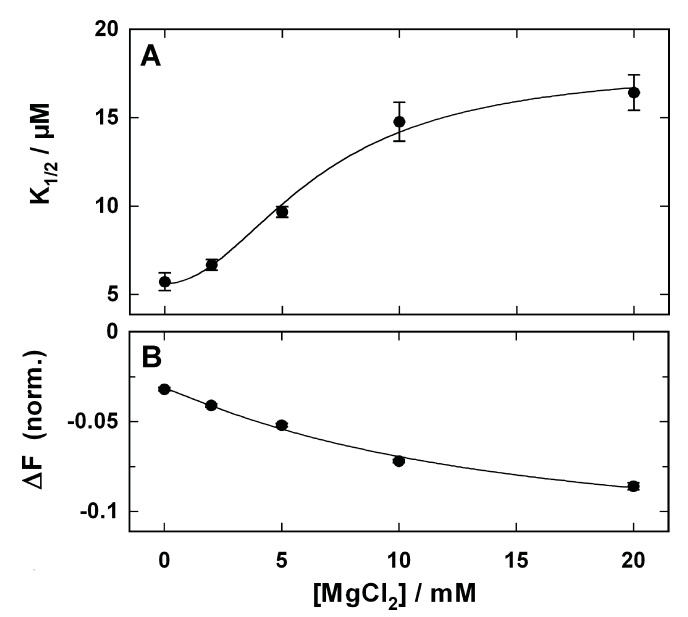

Figure 8. Effect of $\mathrm{Mg}^{2+}$ ions on $\mathrm{K}^{+}$binding in the $\mathrm{E}_{1}$ conformation of solubilized KdpFABC as detected by RH421 fluorescence measure ments. (A) The apparent affinity of $\mathrm{K}^{+}$binding is reduced with increasing $\mathrm{Mg}^{2+}$ concentrations. (B) Maximal fluorescence amplitude, $\Delta F$, obtained by the addition of a saturating $\mathrm{K}^{+}$concentration (500 $\mu \mathrm{M}) . \Delta F$ increased with the $\mathrm{Mg}^{2+}$ concentration and indicates the binding of a larger amount of positive charge.

for the Na,K ATPase, the $K_{1 / 2}$ of $\mathrm{K}^{+}$binding increased with $\mathrm{Mg}^{2+}$ concentration. The apparent reduction in the affinity of $\mathrm{K}^{+}$binding in case of $\mathrm{Na}, \mathrm{K}$ ATPase has been assigned to a Gouy-Chapman effect induced by a $\mathrm{Mg}^{2+}$ ion bound in the vicinity of the entrance of the access channel to the ion binding site. This argument can also be proposed for the observed effects on the KdpFABC complex. $K_{1 / 2}$ increased between 0 and $20 \mathrm{mM} \mathrm{Mg} \mathrm{Mg}^{2+}$ by a factor of $\sim 3$, and the affinity of the assumed $\mathrm{Mg}^{2+}$ binding site can be determined to be $6.6 \mathrm{mM}$ (Figure $8 \mathrm{~A}$ ). Under the same conditions, the amplitude of the maximal fluorescence change upon $\mathrm{K}^{+}$binding, $\Delta F$, increases by a factor of $>2$ (Figure $8 \mathrm{~B}$ ). Because $\Delta F$ is a measure of the amount of charge taken up in the membrane domain, ${ }^{17,22}$ this finding implies that the presence of $\mathrm{Mg}^{2+}$ leads to a larger amount of bound charge. Because it is unlikely that the number of ion binding sites is increased by the presence of $\mathrm{Mg}^{2+}$, an obvious explanation would be that, in the absence of $\mathrm{K}^{+}$and $\mathrm{Mg}^{2+}$, the binding sites are occupied at least partially by $\mathrm{H}^{+}$, and that the Gouy-Chapman effect induced by the presence of $\mathrm{Mg}^{2+}$ leads to a displacement of $\mathrm{H}^{+}$from the binding site(s). As in case of the $\mathrm{Na}, \mathrm{K}$ ATPase, this assumption is further supported by the observation that a $\mathrm{Mg}^{2+}$ titration at $\mathrm{pH} 7.8$ in the absence of $\mathrm{K}^{+}$led to a fluorescence increase of $>2 \%$ at 50 $\mathrm{mM} \mathrm{Mg}^{2+}$ (not shown), which could reflect a $\mathrm{H}^{+}$displacement from the ion binding sites inside the membrane domain. As a consequence, in the presence of increasing $\mathrm{Mg}^{2+}$ concen trations, $\mathrm{K}^{+}$binding is at saturating concentrations no longer an electroneutral exchange of $\mathrm{H}^{+}$against $\mathrm{K}^{+}$, but rather a net uptake of $\mathrm{K}^{+}$(which is reflected by a larger decrease in $\mathrm{RH} 421$ fluorescence).

$\mathrm{DiSC}_{3}(5)$ Fluorescence Measurements with KdpFABC Reconstituted in Lipid Vesicles. KdpFABC containing vesicles were prepared as described in Materials and Methods. Following thermal equilibration, $300 \mathrm{nM} \operatorname{DiSC}_{3}(5)$ and an aliquot of vesicles corresponding to a final concentration of 80 $\mu \mathrm{g} / \mathrm{mL}$ lipid were added. The vesicles contained the same electrolyte with $70 \mathrm{mM} \mathrm{K} \mathrm{SO}_{4}$, to ensure a prolonged pump activity before the lumen of the vesicle is depleted of $\mathrm{K}^{+}$. Once a stable fluorescence signal had been achieved, Mg ATP was added to start ATP driven $\mathrm{K}^{+}$export across the vesicle membrane performed by the inside out oriented KdpFABC fraction (Figure 9A,B). The results show that pumping of $\mathrm{K}^{+}$is electrogenic and that $\mathrm{K}^{+}$is transported out of the vesicles, which is in agreement with previously published results. ${ }^{27,28}$ The stationary fluorescence level obtained after $\sim 250 \mathrm{~s}$ is caused by the fact that the leak current increases with membrane potential, and the potential will not further increase when the leak current equals the oppositely directed pump current. $^{36}$ Because the specific leak conductance of the membrane is an insignificantly varying parameter in different preparations, with an average value of $21 \pm 1 \mathrm{pS} / \mathrm{cm}^{2}$ at $\mathrm{pH}$ 7.2, the stationary fluorescence level is, therefore, a reliable measure of the pump current. Addition of $1 \mu \mathrm{M}$ valinomycin induces a high $\mathrm{K}^{+}$conductance across the vesicle membrane, and the fluorescence level approaches a level corresponding to the $\mathrm{K}^{+}$ equilibrium potential

$$
E_{\mathrm{K}}=R T / F \ln \left(\left[\mathrm{K}^{+}\right]_{\text {in }} /\left[\mathrm{K}^{+}\right]_{\text {out }}\right)
$$

Addition of $0.1 \mathrm{mM}$ P type ATPase inhibitor $o$ vanadate in the ATP induced steady state resulted in inhibition of KdpFABC catalysis. As a consequence, the magnitude of the fluorescence signal increased exponentially to a new steady state (Figure 9B) with a time constant of $47.8 \mathrm{~s}$, which corresponds to a specific membrane conductance of $21 \mathrm{pS} / \mathrm{cm}^{2}$ (assuming $C_{\mathrm{M}}=1 \mu \mathrm{F}$ / $\mathrm{cm}^{2}$ ).

To verify the direction of the ATP induced charge transfer, experiments were performed with plain lipid vesicles containing $140 \mathrm{mM} \mathrm{K}^{+}$inside and $0.14 \mathrm{mM} \mathrm{K} \mathrm{K}^{+}$outside. Ion efflux was initiated by the addition of $1 \mu \mathrm{M}$ valinomycin. When the steady state fluorescence was obtained, increasing concentra tions of $\mathrm{K}^{+}$were added (inset of Figure 9C). The resulting 

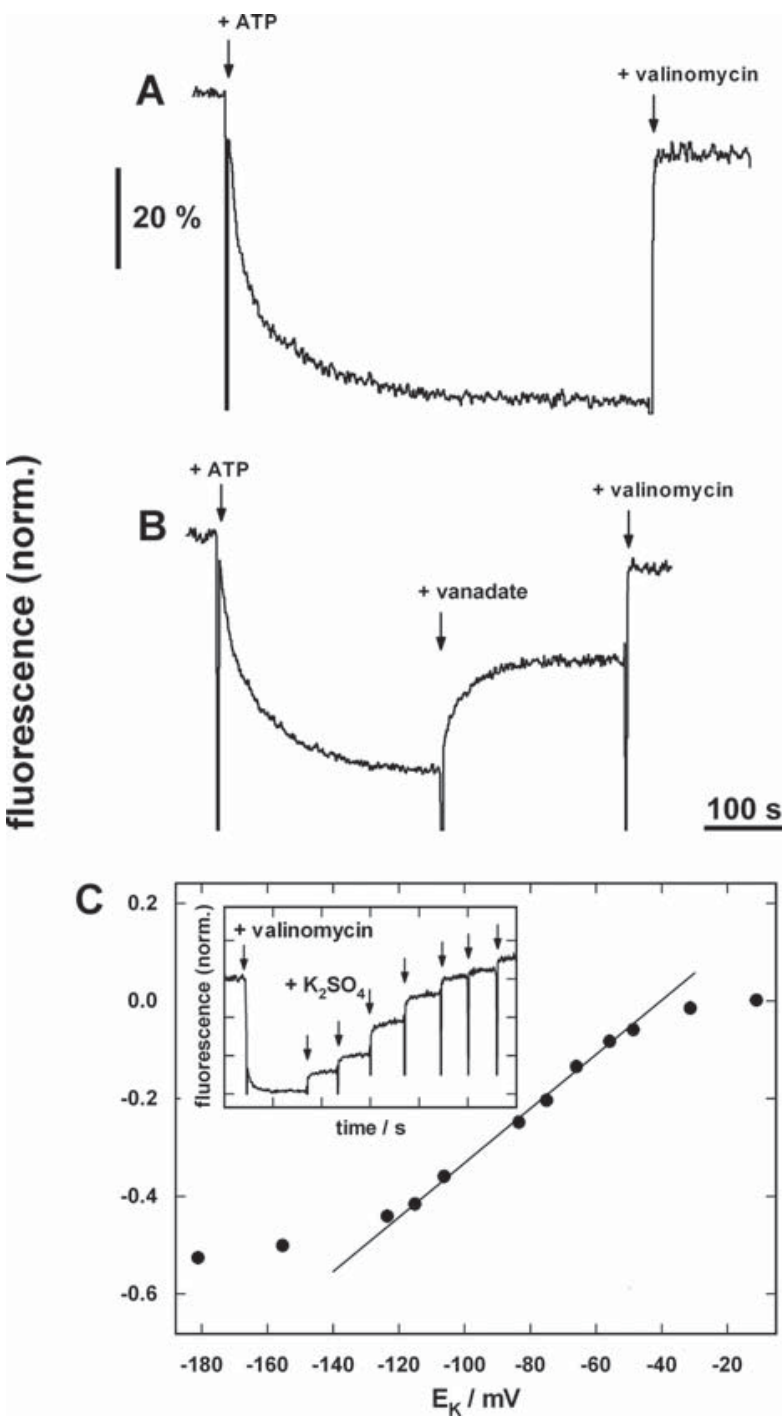

Figure 9. Electrogenic pump activity in $\mathrm{KdpFABC}$ containing vesicles detected by the fluorescent membrane potential indicator $\mathrm{DiSC}_{3}(5)$. (A) Initially, the internal $\mathrm{K}^{+}$concentration equals the outside $\mathrm{K}^{+}$ concentration $(140 \mathrm{mM})$. Addition of $2.5 \mathrm{mM} \mathrm{Mg}$ ATP triggers $\mathrm{K}^{+}$ pumping of $\mathrm{KdpFABC}$, resulting in the export of $\mathrm{K}^{+}$from the vesicles. The increasing inside negative potential is reflected by a fluorescence decrease. Addition of $1 \mu \mathrm{M}$ valinomycin abolishes KdpFABC pump activity and stabilizes the fluorescence level at the Nernst potential, which is controlled by the ratio of $\mathrm{K}^{+}$concentrations inside and outside the vesicles. (B) Same experiment as in panel A. When the ATP induced steady state was reached, $0.1 \mathrm{mM}$ P type ATPase inhibitor $o$ vanadate was added. Consequently, the membrane potential breaks down according to the reduced pump activity and leak conductance of the membrane until a new steady state level is obtained. The collapse of the membrane potential can be fit by a single exponential with a time constant of $47.8 \mathrm{~s}$. (C) Calibration of the fluorescence responses. Plain lipid vesicles loaded with $140 \mathrm{mM} \mathrm{K}^{+}$ were analyzed in buffer with $0.14 \mathrm{mM} \mathrm{K}^{+}$. After equilibration, $1 \mu \mathrm{M}$ valinomycin and, subsequently, aliquots of $\mathrm{K}_{2} \mathrm{SO}_{4}$ were added (as indicated by arrows in the inset). The equilibrium potential (or Nernst potential), $E_{\mathrm{K}}$, was calculated from the $\mathrm{K}^{+}$concentrations inside and outside, and the fluorescence levels were plotted vs the respective $E_{\mathrm{K}}$. The regression line through the data point was used as a calibration curve to estimate the membrane potential obtained in various experiments. steady state fluorescence levels were plotted against the corresponding $\mathrm{K}^{+}$equilibrium potential, $E_{\mathrm{K}}$ (Figure 9C). A linear relationship exists between $E_{\mathrm{K}}$ and the fluorescence level in the voltage range between -120 and $-40 \mathrm{mV}$. The ATP induced fluorescence decrease (Figure 9A,B) indicates an inside negative electric potential. Therefore, it can be stated that the $\mathrm{KdpFABC}$ pump is electrogenic and produces a net extrusion of positive charge from the vesicles as described previ ously. $27,28,30$

The stationary fluorescence level was subsequently used to gain information about the $\mathrm{pH}$ dependence of the pump current and, thus, about the role of $\mathrm{H}^{+}$in the transport process. Experiments as shown in panels A and B of Figure 9 were repeated with the same vesicle preparation under the same conditions except for the $\mathrm{pH}$ that was varied between 6.4 and 7.8. $\mathrm{pH}$ had an only minor effect on specific membrane conductance in this $\mathrm{pH}$ range (6.5-8.2) with an average leak current of $20 \pm 2 \mathrm{pS} / \mathrm{cm}^{2}$, and it did not interfere with the pump current measurements. In Figure 10, the maximal steady

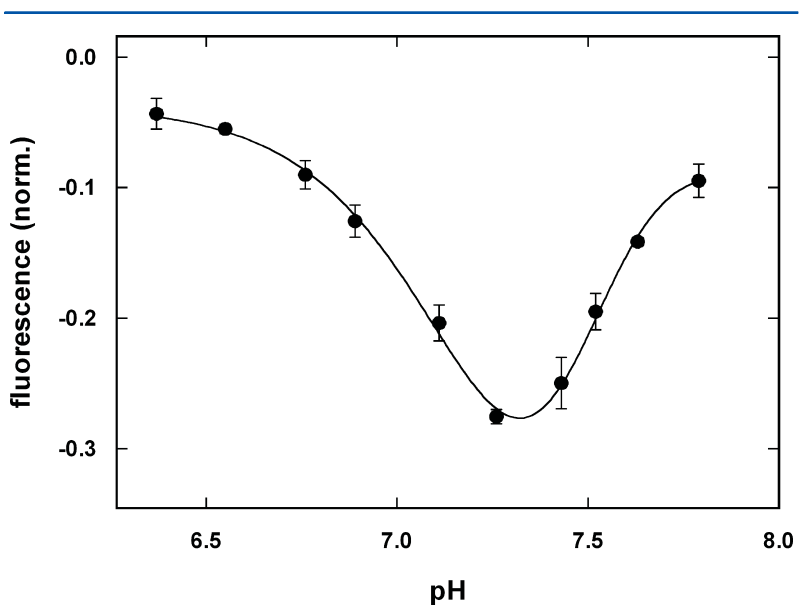

Figure 10. $\mathrm{pH}$ dependence of $\mathrm{K}^{+}$pumping in $\mathrm{KdpFABC}$ vesicles. The maximal fluorescence levels obtained after addition of ATP to vesicles loaded with $140 \mathrm{mM} \mathrm{K}^{+}$inside and $1.4 \mathrm{mM} \mathrm{K}^{+}$outside are plotted vs $\mathrm{pH}$. Because there is a linear correlation between the fluorescence level and the electric membrane potential, $E_{\mathrm{K}}$ (Figure 9C), and under the steady state condition $I_{\text {pump }}=I_{\text {leak }}=\lambda_{\text {leak }} E_{\mathrm{K}}$, the pump current (or pump rate) is proportional to the steady state fluorescence level. The line through the data is a fit with the sum of two Hill functions with a $\mathrm{p} K_{1}$ of $7.21 \pm 0.02$ and a $\mathrm{p} K_{2}$ of $7.50 \pm 0.02$. The data are the means of three experiments ( \pm standard error of the mean).

state level is plotted against $\mathrm{pH}$. As explained above, this level is proportional to the pump current (Figure 9C). The pump current was found to be maximal in the $\mathrm{pH}$ range of 7.3-7.4. At lower and higher $\mathrm{pH}$ values, the pump current decreases significantly. This $\mathrm{pH}$ dependence can be fit by the sum of two Hill functions with $\mathrm{pK}$ values of 7.2 and 7.5 , together with Hill coefficients of $>2$, which indicates that cooperative binding of more than one $\mathrm{H}^{+}$controls the pump current. At low $\mathrm{pH}$, binding of protons reduces the electrogenic pump activity, whereas at high $\mathrm{pH}$, the release of protons inhibits the pump current.

According to Figure $2 \mathrm{~B}$, the low enzyme activity in the absence of $\mathrm{K}^{+}$indicates that a residual $\mathrm{H}^{+}$pump activity may also be expected under these conditions. To study possible electrogenic $\mathrm{H}^{+}$transport by $\mathrm{KdpFABC}$ in the absence of $\mathrm{K}^{+}$, vesicles were prepared in the complete absence of $\mathrm{K}^{+}$; i.e., only 
ultrapure substances and water were used, and no $\mathrm{pH}$ electrode was immersed in the solutions. Figure $11 \mathrm{~A}$ shows a

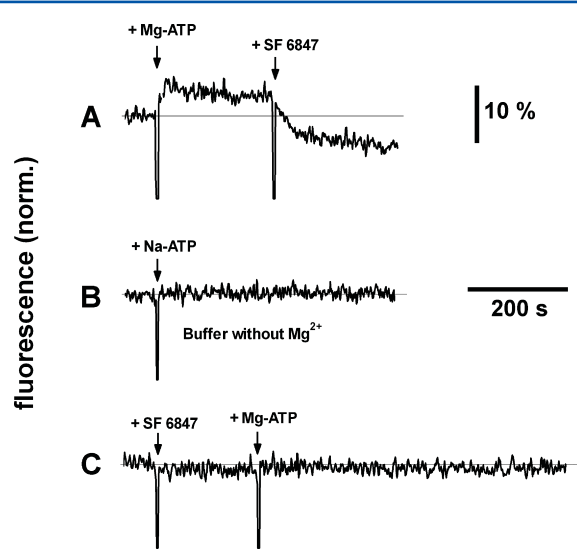

Figure 11. $\mathrm{H}^{+}$transport in reconstituted vesicles prepared in the complete absence of $\mathrm{K}^{+}$. (A) Addition of $1 \mathrm{mM} \mathrm{Mg}$ ATP produced a small fluorescence increase that was stabilized until $10 \mathrm{nM}$ uncoupler SF 6847 had been added that caused a decrease of the fluorescence below the initial level. (B) When in the absence of $\mathrm{Mg}^{2+}, 1 \mathrm{mM} \mathrm{Na}$ ATP was added, no pump activity was possible and no fluorescence change could be detected, indicating that ATP does not affect the fluorescence of the membrane potential detector. (C) The initial addition of $10 \mathrm{nM}$ uncoupler caused a minor fluorescence decrease possibly caused by a small $\mathrm{pH}$ gradient across the membrane. Subsequent addition of Mg ATP induced a slow fluorescence drift to lower values.

corresponding experiment at $\mathrm{pH}$ 7.2. Upon addition of $\mathrm{Mg}$ ATP, a minor fluorescence increase $(\sim 5 \%)$ that reflects an uptake of positive charge inside the vesicles was observed. Subsequently, the fluorescence decreased at an extremely low rate. Addition of the uncoupler SF $6847^{37}$ after $\sim 1100 \mathrm{~s}$ resulted in a further decrease in fluorescence, thereby indicating an intravesicular negative potential. This is in agreement with an equilibrium potential for protons, $E_{\mathrm{H}}$, when the $\mathrm{pH}$ inside is lower than outside as a result of the transport of $\mathrm{H}^{+}$into the vesicles. To exclude artifacts from the addition of ATP and the uncoupler, control experiments were performed. First, addition of $\mathrm{Na}_{2}$ ATP in the absence of $\mathrm{Mg}^{2+}$ in the electrolyte cannot activate the ATPase, and no transport will occur. Correspond ingly, no fluorescence change was observed (Figure 11B). Second, the addition of Mg ATP and the uncoupler was reversed (Figure 11C). Addition of $10 \mathrm{nM} \mathrm{SF} 6847$ induced no significant fluorescence change, which means that no initial $\mathrm{pH}$ gradient is present across the vesicle membrane. Subsequent addition of $1 \mathrm{mM} \mathrm{Mg}$ ATP produced no fluorescence change due to the fact that the uncoupler short circuits the membrane for protons. Third, the experiments were repeated with identical substrate additions to plain lipid vesicles. Because neither Mg ATP nor SF 6847 produced fluorescence artifacts in any control, the Mg ATP induced small fluorescence increase in the absence of the uncoupler indicates a (limited) $\mathrm{H}^{+}$uptake that produced an inside positive potential and a $\mathrm{pH}$ gradient that could be detected in terms of a Nernst potential after addition of the uncoupler. Remarkably, the direction of this $\mathrm{H}^{+}$ translocation would oppose that of $\mathrm{K}^{+}$transport.

\section{DISCUSSION}

The KdpFABC pump is an exciting P type ATPase because in this protein complex the enzymatic and transport activities are distributed between two different subunits. This specialty requires a molecular mechanism that transmits the free enthalpy of ATP hydrolysis from the catalytically active KdpB subunit to the KdpA subunit, where it is utilized to perform ion transport and generate an electrochemical potential gradient for $\mathrm{K}^{+}$across the cytoplasmic membrane of E. coli. To contribute functional details to an analysis of this mechanism, in a first step, the intact protein complex has been isolated and purified in detergent micelles that allow the investigation of electrogenic partial reactions in the pump cycle of the ATPase. This study could be based on recent investigations of both the enzyme activity and the overall transmembrane transport of $\mathrm{K}^{+}$ions in vesicles. ${ }^{1,7,12,24,27,29,30,38,39}$ It has been proven that the $\mathrm{KdpFABC}$ complex transports $\mathrm{K}^{+}$in an electrogenic manner from the periplasmic space to the cytoplasm of E. coli.

When the KdpFABC complex was isolated and purified for this study, a series of detergents was tested to obtain proteindetergent complexes with biochemical properties as close to those of the physiological state as possible. These tests (Table 1) confirmed that the unspecified mixture of detergents, Aminoxide WS 35, is still the best choice. Interestingly, the major component in this mixture, 3 laurylamido $N, N^{\prime}$ dime thylpropyl amine oxide (LAPAO), alone is not sufficient to provide functional properties close to those of the physiological state. Obviously, a minor not yet identified component in the mixture is crucial for enzyme function, thereby possibly mimicking the role of a functional lipid, similar to what has been determined for the Na,K ATPase. ${ }^{40}$ Therefore, mass spectrometric analyses have to be performed to identify the specific component(s).

Enzyme activity could be stimulated not only by the presence of the transported $\mathrm{K}^{+}$ions in a $\mathrm{pH}$ dependent manner but also, to a significantly lesser extent, by $\mathrm{H}^{+}$and $\mathrm{Na}^{+}$. Both these ions seem to act as weak congeners of $\mathrm{K}^{+}$in the absence of $\mathrm{K}^{+}$with respect to stimulation of ATPase activity (Figure 2B). This was shown for all alkali ions and not only for the native protein but also for mutant G232D in the KdpA subunit. ${ }^{30}$

At $\mathrm{pH} 7.8$, an ATP binding affinity $\left(K_{\mathrm{D}}\right)$ of $65 \mu \mathrm{M}$ was determined (Figure $2 \mathrm{C}$ ) together with a maximal activity of $\sim 0.8 \mu \mathrm{mol}$ of $\mathrm{P}_{\mathrm{i}}(\mathrm{mg} \text { of protein })^{-1} \mathrm{~min}^{-1}$ at $37^{\circ} \mathrm{C}$. At higher ATP concentrations, the enzyme activity decreased, and the concentration dependence of this inhibition could be fit only by the Hill function with a Hill coefficient of 2.1 and a half inhibiting concentration of $1.54 \mathrm{mM}$. Although the high Hill coefficient indicates that this inhibitory effect of ATP depends on a cooperative action of two ATP molecules, a mechanistic explanation for this observation cannot be given so far. A recent analysis of the ATP binding mechanism in KdpFABC does not reflect the potential concomitant action of two ATP molecules. $^{13}$

The effect of $\mathrm{pH}$ on enzyme activity raises the question of what role the $\mathrm{H}^{+}$plays in the function of the ion pump. On one hand, numerous amino acid side chains are prone to (de)protonation and may affect enzyme and/or transport function in an unspecific manner. On the other hand, because in the absence of $\mathrm{K}^{+}$a small but significant enzyme activity was detected, $\mathrm{H}^{+}$could bind also to specific sites, thereby generating either allosteric effects on the $\mathrm{KdpB}$ subunit or direct competition in the ion binding sites of $\mathrm{KdpA}$. 
In the RH421 experiments with detergent solubilized KdpFABC complexes, it could be demonstrated that binding of $\mathrm{K}^{+}$as well as of $\mathrm{H}^{+}$and $\mathrm{Na}^{+}$produced a fluorescence decrease in both its unphosphorylated and phosphorylated states (Figures 3-6). This response is due to an uptake of positive charge into binding sites inside the membrane domain of the protein. ${ }^{17,18,22}$ The $\mathrm{K}^{+}$binding sites are known to be located in the transmembrane section of the KdpA subunit., ${ }^{7,28}$ Two important conclusions can be drawn from the experimental data. (1) Because the fluorescence decrease induced by $\mathrm{K}^{+}$is rather unaffected by $\mathrm{H}^{+}$and vice versa, $\mathrm{K}^{+}$ and $\mathrm{H}^{+}$bind preferentially to different sites in the membrane domain. An electroneutral exchange of $\mathrm{K}^{+}$for $\mathrm{H}^{+}$(and vice versa) contributes only a small fraction to this process. In the unphosphorylated state, an increase in the $\mathrm{H}^{+}$concentration by a factor of 100 decreased the amount of $\mathrm{K}^{+}$bound electrogenically by only $20 \%$ (Figure 4 ). Similarly, an increase in the $\mathrm{K}^{+}$concentration from 0 to $500 \mu \mathrm{M}$ decreases the amount of electrogenically bound $\mathrm{H}^{+}$by only $\sim 15 \%$. This means that (more than) $80 \%$ of $\mathrm{K}^{+}$and $\mathrm{H}^{+}$binding occurs independently. (2) The phosphorylation of KdpFABC by either ATP or $\mathrm{P}_{\mathrm{i}}$ produced in the presence of a saturating $\mathrm{K}^{+}$ concentration no significant fluorescence changes. This implies that in both phosphorylation inducing reaction sequences the amount of charge in the binding sites remains constant when the same $\mathrm{pH}$ and saturating $\mathrm{K}^{+}$concentration are present on both sides of the membrane (a condition that is inevitable in the experiments with the solubilized protein). Via application of the Post-Albers cycle for KdpFABC, the ATP induced reaction sequence starts with enzyme phosphorylation, accompanied by ion occlusion, followed by the conformation transition, $\mathrm{E}_{1} \rightarrow$ $\mathrm{E}_{2}$, and subsequent deocclusion of the ion binding sites on the opposite side of the membrane. The backdoor phosphorylation by $P_{i}$ is the reversal reaction of the dephosphorylation step, and the electrogenicity has to be the same for both forward and backward reactions. Therefore, it can be concluded that the location of the binding site(s) inside KdpA is not significantly displaced by the phosphorylation and dephosphorylation reaction in the KdpFABC complex.

Additional properties of the ion binding and release reactions of the KdpFABC complex can be obtained from the analyses of the titration experiments (Figures 5-8). The binding affinities for both ions, $\mathrm{K}^{+}$and $\mathrm{H}^{+}$, were found to be different in the unphosphorylated and phosphorylated states. Phosphorylation increased $K_{1 / 2}$ by a factor of $\sim 2.2-2.4$ at $\mathrm{pH} 7.8$. At $\mathrm{pH} 6.1$, this effect is even more pronounced (a factor of $\sim 3.8-4.5$ ) (Table 2 ), and there was no significant difference regardless of whether the phosphorylation was performed by ATP or $\mathrm{P}_{\mathrm{i}}$. The corresponding Lineweaver-Burk plot (Figure 7) demonstrates a mixed inhibition for $\mathrm{K}^{+}$binding with respect to the $\mathrm{H}^{+}$. As already mentioned, direct $\mathrm{H}^{+}$versus $\mathrm{K}^{+}$competition contributes only a minor fraction to the observed effects. A possible mechanism for the major noncompetitive fraction of inhibition could be an electrostatic (Coulomb) interaction, in a way that the presence of the positively charged $\mathrm{H}^{+}$bound to independent sites within KdpA generates a Debye-Hückel type repulsion of $\mathrm{K}^{+}$that is reflected in a lower apparent affinity of the $\mathrm{K}^{+}$binding sites.

The $\mathrm{pK}$ of $\sim 7.6$ of $\mathrm{H}^{+}$binding in the unphosphorylated enzyme was reduced to $\sim 7.1$ when the enzyme was phosphorylated by $\mathrm{P}_{\mathrm{i}}$ and to $\sim 6.8$ when the enzyme was phosphorylated by ATP. The difference with respect to the type of phosphorylation is remarkable because it implies that higher
$\mathrm{H}^{+}$concentrations are necessary to stabilize $\mathrm{H}^{+}$binding in the phosphorylated state under turnover conditions (i.e., when the enzyme is phosphorylated by ATP). When phosphorylated by $\mathrm{P}_{\mathrm{i}}$, the pumps are trapped in the $\mathrm{PE}_{2}$ conformation. When phosphorylated by ATP, the pump is able to run under turnover conditions. A straightforward interpretation of the detected difference in $\mathrm{pK}$ is that the phosphorylated state of the enzyme is short lived under turnover conditions when the ion sites, which are able to bind protons, are not (fully) protonated. The experimental result implies that under turnover conditions higher proton concentrations are necessary to stabilize the phosphorylated state. The $\mathrm{P}_{2}$ conformation stabilizing effect of protons further indicates, on the other hand, that bound protons may not be transported in the subsequent dephosphorylation cycle.

Mechanistic Implications. This information can be applied in analyzing the underlying reaction mechanism based on the Post-Albers cycle. Its general form (Figure 12A) describes a ping pong mechanism that has been shown for all type II P type ATPases that translocate two different ion species in opposite directions across the membrane. ${ }^{41}$ There fore, the entire process can be divided into two half cycles. In the half cycle driven by ATP hydrolysis, ions are transported out of the cytoplasm. In the second half cycle driven by dephosphorylation, counterions are moved into the cytoplasm. The KdpFABC pump, which is a type Ia P type ATPase, ${ }^{42}$ translocates $\mathrm{K}^{+}$ions into the cytoplasm, and no counter transport of a second ion species has been detected. Two different scenarios could account for this observation. First, inward ion transport takes place in the dephosphorylation half cycle, whereas in the ATP driven half cycle, no ions are transported (Figure 12B). This would correspond to the pump cycle of the type II P type ATPases and was suggested many years ago. ${ }^{27,33}$ A second proposal would be the $\mathrm{K}^{+}$transport in the ATP hydrolyzing half cycle while no ions are translocated in the dephosphorylation half cycle (Figure 12C). This implies, however, that the transport direction is reversed with respect to the pump mode of type II P type ATPases. This proposal was introduced by Bramkamp and Altendorf. ${ }^{29}$ Such a fundamental modification of the Post-Albers scheme can be justified by the fact that in the KdpFABC complex two protein subunits are coupled to perform the ATP driven ion transport. This allows an additional degree of freedom compared to that in the type II $\mathrm{P}$ type ATPases in which enzyme and transport function are located in the same subunit. The experimental results available so far do not allow a discrimination between these models.

Additionally, these models do not consider the role of protons that are bound to binding sites inside the membrane domain. These protons perform at least two different functions.

The first one is the action as a poorly adapted congener of $\mathrm{K}^{+}$ that can be transported with low efficiency in the absence of $\mathrm{K}^{+}$, as observed previously for $\mathrm{Rb}^{+}, \mathrm{Na}^{+}$, and $\mathrm{Li}^{+}{ }^{+30,43,44}$ In this process, the ions are bound to the "transport" binding sites where competition occurs when $\mathrm{K}^{+}$is also present. $\mathrm{H}^{+}$may bind to these sites after the release of $\mathrm{K}^{+}$at low $\mathrm{pH}$ values on the cytoplasmic side, and this "back binding" kinetically blocks the pump from continuing through the pump cycle, which requires empty binding sites. This would explain the reduced enzyme activity (Figure 2B) and the reduced level of transport of $\mathrm{K}^{+}$out of vesicles (Figure 10) at low $\mathrm{pH}$ values. However, in the total absence of $\mathrm{K}^{+}$, a sparse transport of $\mathrm{H}^{+}$into the vesicles could be observed (Figure 11A). This finding may be interpreted as a low rate "counter transport" with respect to the 

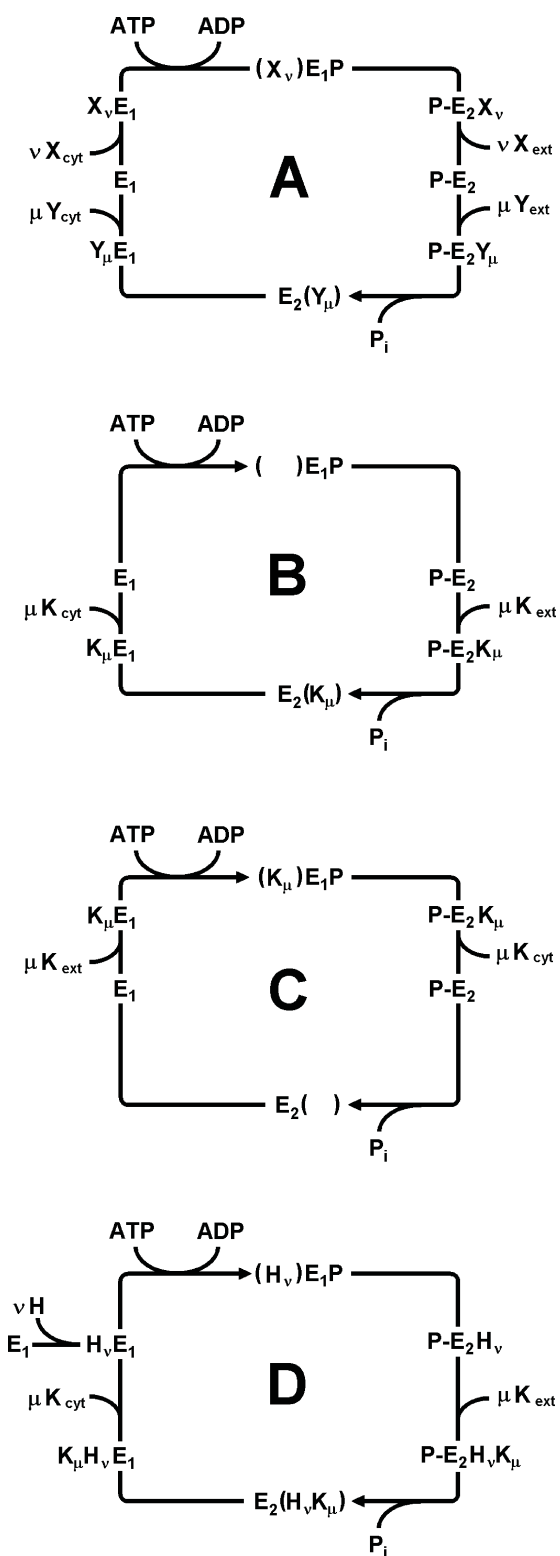

Figure 12. Post-Albers pump cycles of $P$ type ATPases and proposals of modifications for the KdpFABC pump. (A) General scheme of the pump cycle, valid for type II P type ATPases such as $\mathrm{Na}, \mathrm{K}$ ATPase, SR Ca ATPase, and H,K ATPase, ${ }^{4}$ and a template for the function of type I pumps. (B-D) Derived proposals for the KdpFABC pump (see the text).

physiologically relevant $\mathrm{K}^{+}$transport facilitated in these binding sites. So far, it is not clear whether this mode occurs only in the absence of $\mathrm{K}^{+}$or whether it is a kind of undesired slippage that cannot be prevented completely by the protein.

The second function of $\mathrm{H}^{+}$is noncompetitive binding. It was found that $\mathrm{H}^{+}$binding is an electrogenic process (Figure 4) and that the transport activity decreased above $\mathrm{pH} 7.5$ with a Hill coefficient of $>2$ (Figure 10). The electrogenicity indicates that binding sites come into play that are localized within the membrane domain. They may be localized in principle either in one functionally coupled subunit or in both, KdpA and KdpB. One proposal to include this role of $\mathrm{H}^{+}$in the pump cycle is shown in Figure 12D. The Post-Albers cycle is adapted from the more "classical" type (Figure 12B) in which $\mathrm{K}^{+}$is translocated in the dephosphorylation half cycle. In addition, protons bind to sites that have to be occupied to allow enzyme phosphorylation without being transported across the mem brane. The protons remain "occluded" in the sites throughout the whole cycle, and their presence inside the membrane domain is a prerequisite for the ATP driven half cycle. Two options appear to be possible. (1) The binding sites are located in the KdpA subunit, where the trapped $\mathrm{H}^{+}$would act as a surrogate of the primarily transported ion in type II P type ATPases. In this case, the protons may, however, escape with a low probability from the occluded state, at least in the absence of $\mathrm{K}^{+}$. Thus, $\mathrm{H}^{+}$may be lost to the extracellular side in the phosphorylated state, $\mathrm{P}_{2}$, and cause a delayed transition to the dephosphorylation step and return to the $\mathrm{E}_{1}$ conformation with the binding sites accessible to the cytoplasmic side. (2) An alternative would be that the binding sites are localized in the $\mathrm{KdpB}$ subunit as an allosteric factor that allows the transfer of energy from $\mathrm{KdpB}$ to KdpA. A supportive argument for such an arrangement would be the observed $\mathrm{pH}$ dependence of enzyme activity (Figure $2 \mathrm{~B}$ ) that exhibited no decrease at $\mathrm{pH}>7.5$. This behavior would imply a less than strict coupling of KdpA and $\mathrm{KdpB}$ that allows a dissipative ATP hydrolysis with a detectable probability but without ion transport (Figure 10), which would be, however, a rather unfavorable condition for the cell. The analysis of the fluorescence decrease in the RH421 experiments obtained upon binding of $\mathrm{K}^{+}$and $\mathrm{H}^{+}$at or close to saturating concentrations (Figures 3-5) allows an estimation of the maximal amount of charge bound to the binding sites. The maximal fluorescence decrease obtained in the unphosphory lated conformation upon $\mathrm{K}^{+}$binding is on the order of 0.4; with $\mathrm{H}^{+}$binding, it is $\sim 0.6$. So far, in the case of $\mathrm{KdpFABC}$, there is no absolute measure of the maximal number of ions bound. However, because charge is quantized, the normalized fluorescence changes of 0.4 and 0.6 could account for two $\mathrm{K}^{+}$ and three $\mathrm{H}^{+}$ions in the sites. While potassium ions have to be bound in sites in which they are coordinated by several oxygen atoms from amino acid side chains, $\mathrm{H}^{+}$may bind directly to single charged amino acid side chains. According to Becker et al., ${ }^{28}$ Arg493 in KdpA may play a key role in this context. A stoichiometry of two $\mathrm{K}^{+}$ions transported per ATP hydrolyzed is feasible according to a simple, conservative estimate. Assuming a membrane potential in E. coli of $-140 \mathrm{mV},{ }^{45}$ a cytoplasmic $\mathrm{K}^{+}$concentration of $180 \mathrm{mM}^{46}$ a Gibbs free enthalpy of $-50 \mathrm{~kJ} / \mathrm{mol}$ for the ATP hydrolysis, and a low extracellular $\mathrm{K}^{+}$concentration of $2 \mu \mathrm{M}$ (a condition under which $\mathrm{KdpFABC}$ will be expressed and active), the electro chemical potential gradient for $\mathrm{K}^{+}$is $14.9 \mathrm{~kJ} / \mathrm{mol}$. Compared to the energy provided by ATP hydrolysis, up to three $\mathrm{K}^{+}$ions could be transferred across the membrane under physiological conditions. Protons do not have to be considered because they are assumed to remain occluded and are not transported.

A more reliable characterization of the pump cycle of $\mathrm{KdpFABC}$ will need more detailed investigations, and in particular, highly resolved structural information will allow a definitive mapping of the ion binding sites and their occupation. Further experiments on transport properties and attempts to crystallize the protein complex are underway.

\section{AUTHOR INFORMATION}

\section{Corresponding Author}

*Phone: +49 7531 882253. Fax: +49 7531 883183. E mail: h j. apell@uni konstanz.de. 


\section{Funding}

We gratefully acknowledge funding from the Konstanz Research School of Chemical Biology (University of Konstanz). J. C.G. was supported by the Deutsche Forschungsgemein schaft (Grant GR2698/1 1).

\section{Notes}

The authors declare no competing financial interests.

\section{ACKNOWLEDGMENTS}

We thank Dr. Wolfram Welte for support and fruitful discussion.

\section{ABBREVIATIONS}

Fos choline 12, $n$ dodecylphosphocholine; $\beta$ DDM, $n$ dodecyl $\beta$ D maltoside; $\beta$ DM, $n$ decyl $\beta$ D maltoside; PCC $\alpha \mathrm{M}$, trans 4 (trans 4 ' propylcyclohexyl)cyclohexyl $\alpha$ D maltoside; LAPAO, 3 laurylamido $N, N^{\prime}$ dimethylpropyl amine oxide; $\mathrm{DiSC}_{3}(5), 3,3^{\prime}$ dipropylthiadicarbocyanine iodide.

\section{REFERENCES}

(1) Harold, F. M., and Altendorf, K. (1974) Cation transport in bacteria; $\mathrm{K}^{+}, \mathrm{Na}^{+}$and $\mathrm{H}^{+}$. Curr. Top. Membr. Transp. 5, 1-50.

(2) Helmer, G. L., Laimins, L. A., and Epstein, W. (1982) Mechanism of potassium transport in bacteria. In Membranes and Transport (Martonosi, A. N., Ed.) pp 123-128, Plenum Publishing Corp., New York.

(3) Laimins, L. A., Rhoads, D. B., Altendorf, K., and Epstein, W. (1978) Identification of the structural proteins of an ATP driven potassium transport system in Escherichia coli. Proc. Natl. Acad. Sci. U.S.A. 75, 3216-3219.

(4) Epstein, W. (1985) The Kdp system: A bacterial $\mathrm{K}^{+}$transport ATPase. Curr. Top. Membr. Transp. 23, 153-175.

(5) Rhoads, D. B., Waters, F. B., and Epstein, W. (1976) Cation transport in Escherichia coli. VIII. Potassium transport mutants. J. Gen. Physiol. 67, 325-341.

(6) Durell, S. R., Bakker, E. P., and Guy, H. R. (2000) Does the KdpA subunit from the high affinity $\mathrm{K}^{+}$translocating $\mathrm{P}$ type KDP ATPase have a structure similar to that of $\mathrm{K}^{+}$channels? Biophys. J. 78, 188-199.

(7) Greie, J. C., and Altendorf, K. (2007) The $\mathrm{K}^{+}$translocating KdpFABC complex from Escherichia coli: A P type ATPase with unique features. J. Bioenerg. Biomembr. 39, 397-402.

(8) Møller, J. V., Juul, B., and le Maire, M. (1996) Structural organization, ion transport, and energy transduction of $\mathrm{P}$ type ATPases. Biochim. Biophys. Acta 1286, 1-51.

(9) Axelsen, K. B., and Palmgren, M. G. (1998) Evolution of substrate specificities in the P type ATPase superfamily. J. Mol. Evol. 46, 84-101.

(10) Gaßel, M., and Altendorf, K. (2001) Analysis of KdpC of the $\mathrm{K}^{+}$ transporting KdpFABC complex of Escherichia coli. Eur. J. Biochem. $268,1772-1781$.

(11) Therien, A. G., Karlish, S. J., and Blostein, R. (1999) Expression and functional role of the $\gamma$ subunit of the Na,K ATPase in mammalian cells. J. Biol. Chem. 274, 12252-12256.

(12) Ahnert, F., Schmid, R., Altendorf, K., and Greie, J. C. (2006) ATP binding properties of the soluble part of the $\mathrm{KdpC}$ subunit from the Escherichia coli $\mathrm{K}^{+}$transporting $\mathrm{KdpFABC}$ P type ATPase. Biochemistry 45, 11038-11046.

(13) Irzik, K., Pfrötzschner, J., Goss, T., Ahnert, F., Haupt, M., and Greie, J. C. (2011) The KdpC subunit of the Escherichia coli $\mathrm{K}^{+}$ transporting KdpB P type ATPase acts as a catalytic chaperone. FEBS J. 278, 3041-3053.

(14) Gaßel, M., Möllenkamp, T., Puppe, W., and Altendorf, K. (1999) The KdpF subunit is part of the $\mathrm{K}^{+}$translocating Kdp complex of Escherichia coli and is responsible for stabilization of the complex in vitro. J. Biol. Chem. 274, 37901-37907.
(15) Albers, R. W. (1967) Biochemical aspects of active transport. Annu. Rev. Biochem. 36, 727-756.

(16) Post, R. L., Hegyvary, C., and Kume, S. (1972) Activation by adenosine triphosphate in the phosphorylation kinetics of sodium and potassium ion transport adenosine triphosphatase. J. Biol. Chem. 247, $6530-6540$.

(17) Bühler, R., Stürmer, W., Apell, H. J., and Läuger, P. (1991) Charge translocation by the Na,K pump: I. Kinetics of local field changes studied by time resolved fluorescence measurements. J. Membr. Biol. 121, 141-161.

(18) Stürmer, W., Bühler, R., Apell, H. J., and Läuger, P. (1991) Charge translocation by the $\mathrm{Na}, \mathrm{K}$ pump: II. Ion binding and release at the extracellular face. J. Membr. Biol. 121, 163-176.

(19) Apell, H. J., Roudna, M., Corrie, J. E., and Trentham, D. R. (1996) Kinetics of the phosphorylation of $\mathrm{Na}, \mathrm{K}$ ATPase by inorganic phosphate detected by a fluorescence method. Biochemistry 35, $10922-10930$.

(20) Schneeberger, A., and Apell, H. J. (2001) Ion selectivity of the cytoplasmic binding sites of the Na,K ATPase: II. Competition of various cations. J. Membr. Biol. 179, 263-273.

(21) Apell, H. J., and Diller, A. (2002) Do $\mathrm{H}^{+}$ions obscure electrogenic $\mathrm{Na}^{+}$and $\mathrm{K}^{+}$binding in the $\mathrm{E}_{1}$ state of the $\mathrm{Na}, \mathrm{K}$ ATPase? FEBS Lett. 532, 198-202.

(22) Habeck, M., Cirri, E., Katz, A., Karlish, S. J., and Apell, H. J. (2009) Investigation of electrogenic partial reactions in detergent solubilized Na,K ATPase. Biochemistry 48, 9147-9155.

(23) Siebers, A., and Altendorf, K. (1988) The $\mathrm{K}^{+}$translocating Kdp ATPase from Escherichia coli. Purification, enzymatic properties and production of complex and subunit specific antisera. Eur. J. Biochem. $178,131-140$.

(24) Heitkamp, T., Kalinowski, R., Böttcher, B., Börsch, M., Altendorf, K., and Greie, J. C. (2008) $\mathrm{K}^{+}$Translocating KdpFABC P Type ATPase from Escherichia coli Acts as a Functional and Structural Dimer. Biochemistry 47, 3564-3575.

(25) Vagin, O., Denevich, S., Munson, K., and Sachs, G. (2002) SCH28080, a $\mathrm{K}^{+}$competitive inhibitor of the gastric H,K ATPase, binds near the M5-6 luminal loop, preventing $\mathrm{K}^{+}$access to the ion binding domain. Biochemistry 41, 12755-12762.

(26) Lambert, O., Levy, D., Ranck, J. L., Leblanc, G., and Rigaud, J. L. (1998) A new "gel like" phase in dodecyl maltoside lipid mixtures: Implications in solubilization and reconstitution studies. Biophys. J. 74, 918-930.

(27) Fendler, K., Dröse, S., Altendorf, K., and Bamberg, E. (1996) Electrogenic $\mathrm{K}^{+}$transport by the Kdp ATPase of Escherichia coli. Biochemistry 35, 8009-8017.

(28) Becker, D., Fendler, K., Altendorf, K., and Greie, J. C. (2007) The conserved dipole in transmembrane helix 5 of $\mathrm{KdpB}$ in the Escherichia coli KdpFABC P type ATPase is crucial for coupling and the electrogenic $\mathrm{K}^{+}$translocation step. Biochemistry 46, 13920-13928.

(29) Bramkamp, M., and Altendorf, K. (2005) Single amino acid substitution in the putative transmembrane helix $\mathrm{V}$ in $\mathrm{KdpB}$ of the KdpFABC complex of Escherichia coli uncouples ATPase activity and ion transport. Biochemistry 44, 8260-8266.

(30) Schrader, M., Fendler, K., Bamberg, E., Gaßel, M., Epstein, W., Altendorf, K., and Dröse, S. (2000) Replacement of glycine 232 by aspartic acid in the KdpA subunit broadens the ion specificity of the $\mathrm{K}^{+}$translocating KdpFABC complex. Biophys. J. 79, 802-813.

(31) Hoffman, J. F., and Laris, P. C. (1974) Determination of membrane potentials in human and Amphiuma red blood cells by means of fluorescent probe. J. Physiol. 239, 519-552.

(32) Hovers, J., Potschies, M., Polidori, A., Pucci, B., Raynal, S., Bonnete, F., Serrano Vega, M. J., Tate, C. G., Picot, D., Pierre, Y., Popot, J. L., Nehme, R., Bidet, M., Mus Veteau, I., Busskamp, H., Jung, K. H., Marx, A., Timmins, P. A., and Welte, W. (2011) A class of mild surfactants that keep integral membrane proteins water soluble for functional studies and crystallization. Mol. Membr. Biol. 28, 171-181.

(33) Siebers, A., and Altendorf, K. (1989) Characterization of the phosphorylated intermediate of the $\mathrm{K}^{+}$translocating Kdp ATPase from Escherichia coli. J. Biol. Chem. 264, 5831-5838. 
(34) Andersen, J. P., and Vilsen, B. (1996) Primary ion pumps. In Cell chemistry and physiology (Bittar, E. E., and Bittar, N., Eds.) pp 166, JAI Press Inc., Greenwich, CT.

(35) Schneeberger, A., and Apell, H. J. (1999) Ion selectivity of the cytoplasmic binding sites of the Na,K ATPase: I. Sodium binding is associated with a conformational rearrangement. J. Membr. Biol. 168, $221-228$.

(36) Apell, H. J., and Bersch, B. (1987) Oxonol VI as an optical indicator for membrane potentials in lipid vesicles. Biochim. Biophys. Acta 903, 480-494.

(37) Terada, H. (1975) Some biochemical and physiochemical properties of the potent uncoupler SF 6847 (3,5 di tert butyl 4 hydroxybenzylidenemalononitrile). Biochim. Biophys. Acta 387, 519532 .

(38) Gaßel, M., Siebers, A., Epstein, W., and Altendorf, K. (1998) Assembly of the Kdp complex, the multi subunit $\mathrm{K}^{+}$transport ATPase of Escherichia coli. Biochim. Biophys. Acta 1415, 77-84.

(39) Fendler, K., Dröse, S., Epstein, W., Bamberg, E., and Altendorf, K. (1999) The Kdp ATPase of Escherichia coli mediates an ATP dependent, $\mathrm{K}^{+}$independent electrogenic partial reaction. Biochemistry 38, 1850-1856.

(40) Haviv, H., Habeck, M., Kanai, R., Toyoshima, C., and Karlish, S. J. (2013) Neutral phospholipids stimulate Na,K ATPase activity: A specific lipid protein interaction. J. Biol. Chem. 288, 10073-10081.

(41) Apell, H. J. (2003) Structure Function Relationship in P Type ATPases: A Biophysical Approach. Rev. Physiol. Biochem. Pharmacol. $150,1-35$.

(42) Bramkamp, M., Altendorf, K., and Greie, J. C. (2007) Common patterns and unique features of $\mathrm{P}$ type ATPases: A comparative view on the KdpFABC complex from Escherichia coli. Mol. Membr. Biol. 24, 375-386.

(43) Buurman, E. T., Kim, K. T., and Epstein, W. (1995) Genetic evidence for two sequentially occupied $\mathrm{K}^{+}$binding sites in the $\mathrm{Kdp}$ transport ATPase. J. Biol. Chem. 270, 6678-6685.

(44) Bertrand, J., Altendorf, K., and Bramkamp, M. (2004) Amino acid substitution in the putative selectivity filter regions III and IV in $\mathrm{KdpA}$ alter ion selectivity of the KdpFABC complex from Escherichia coli. J. Bacteriol. 186, 5519-5522.

(45) Bot, C. T., and Prodan, C. (2010) Quantifying the membrane potential during E. coli growth stages. Biophys. Chem. 146, 133-137.

(46) Shabala, L., Bowman, J., Brown, J., Ross, T., McMeekin, T., and Shabala, S. (2009) Ion transport and osmotic adjustment in Escherichia coli in response to ionic and non ionic osmotica. Environ. Microbiol. 11, 137-148.

(47) Apell, H. J. (2004) How do P type ATPases transport ions? Bioelectrochemistry 63, 149-156. 